ADÉRSON OMAR MOURÃO CINTRA DAMIÃO

\title{
HIPOMOTILIDADE DA VESÍCULA BILIAR EM PACIENTES COLECTOMIZADOS POR RETOCOLITE ULCERATIVA INESPECÍFICA
}

Tese apresentada à Faculdade de Medicina da Universidade de São Paulo para obtenção do título de Doutor em Medicina

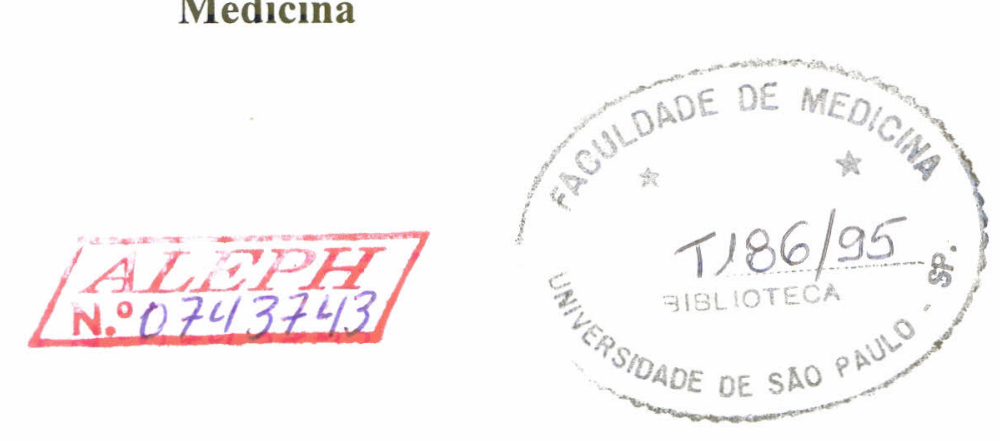

São Paulo 
ADÉRSON OMAR MOURÃO CINTRA DAMIÃO

HIPOMOTILIDADE DA VESÍCULA BILIAR EM PACIENTES

COLECTOMIZADOS POR RETOCOLITE ULCERATIVA INESPECÍFICA

Tese apresentada à Faculdade de Medicina da Universidade de São Paulo para obtenção do título de Doutor em Medicina

Área de Concentração: Gastroenterologia Clínica

Orientador: Prof. Dr. Eder C.R. Quintão

São Paulo

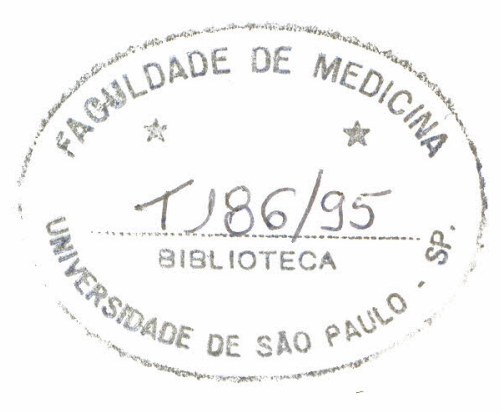

1995 

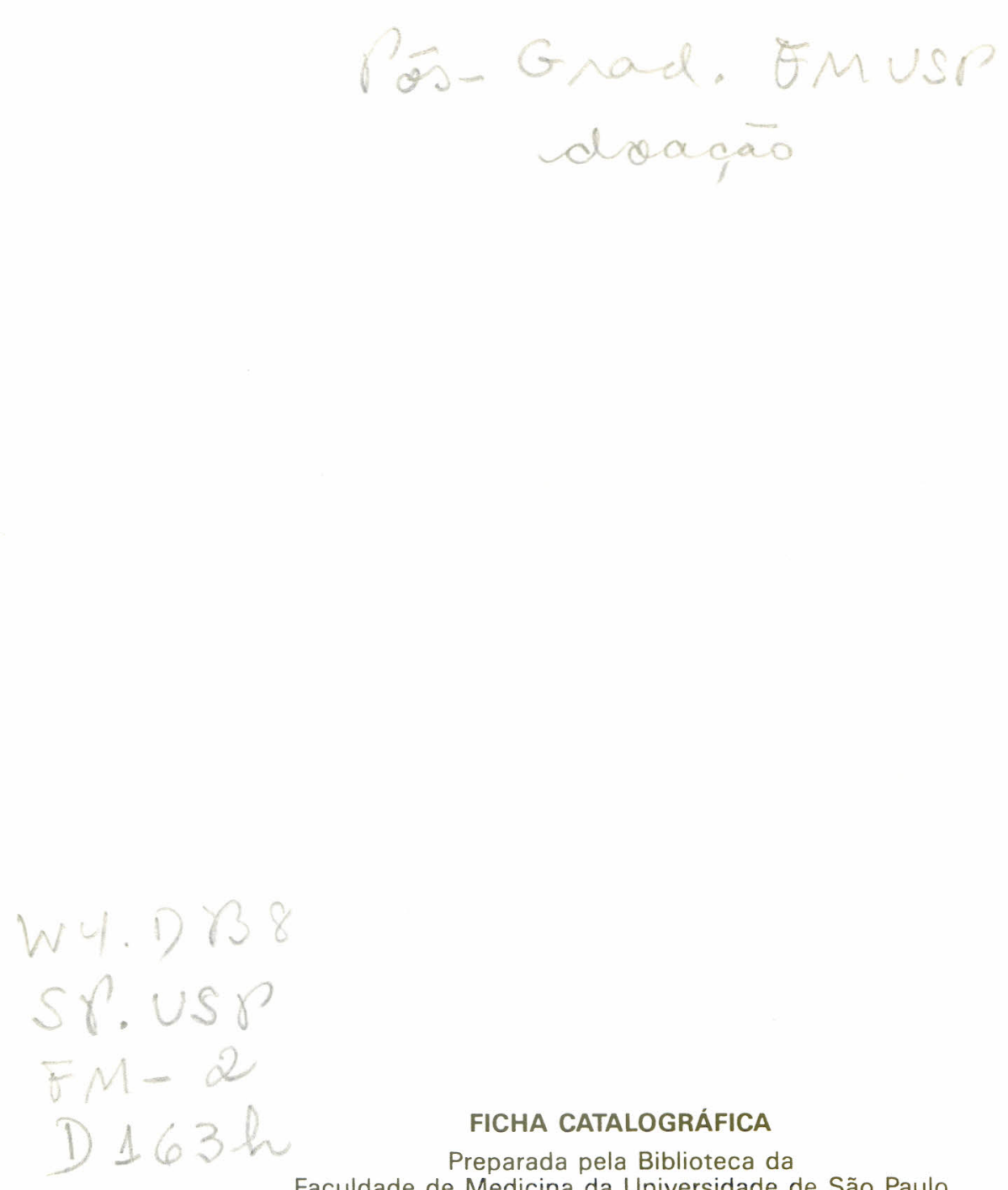

FICHA CATALOGRÁFICA

Preparada pela Biblioteca da

Faculdade de Medicina da Universidade de São Paulo

Damiāo, Adērson Omar Mourāo Cintra

Hipomotilidade da vesícula biliar em pacientes colectomi zados por retocolite ulcerativa inespecifica / Adérson Omar Mourāo Cintra Damiāo. -- Sāo Paulo, 1995.

Tese (doutorado)--Faculdade de Medicina da Universidade

de Sāo Pau1o. Departamento de Gastroenterologia.

Ảrea de concentraçāo: Gastroenterologia Clínica.

Orientador: Eder C. R. Quintāo.

Descritores: 1.COLITE ULCERATIVA/diagnóstico 2.COLECTO MIA/efeitos adversos 3.COLELITIASE/fisiopatologia 4.MOTI= LIDADE GASTROINTESTINAL/fisiologia 5.VESICULA BILIAR/fisio patologia 6.VESICULA BILIAR/ultrasonografia 7.ULTRASONOGRA $\mathrm{FIA} /$ métodos

USP/FM-SBD-133/95 
Este trabalho foi realizado na Disciplina de Gastrenterologia Clínica do Departamento de Gastrenterologia da Faculdade de Medicina da Universidade de São Paulo (FMUSP), no Laboratório de Investigação Médica em Gastrenterologia do Hospital das Clínicas da FMUSP (HCFMUSP-LIM 07) e no Setor de Ultra-sonografia do Instituto do Coração do HCFMUSP. 
"Se aprendi alguma coisa com o rápido desenrolar na linha do tempo, foram as virtudes da tolerância, da moderação em pensamentos e atos, da compreensão para com meu semelhante."

A.J. Cronin 
Dedico este trabalho

a meus pais, Maria Clemência e Josué, pela educação e formação que me deram e por terem em mim incutido o valor do estudo.

a minha amada esposa, Elaine, que mais uma vez esteve do meu lado, apoiando me e encorajando me ao longo de toda esta jornada.

a meus filhos, Lucas e Marilia, que, à maneira deles, souberam compreender a minha ausência. 


\section{AGRADECIMENTOS}

Ao Prof. Dr. Antonio Atílio Laudanna que, como ninguém, tem acompanhado e estimulado minha carreira na Univesidade de São Paulo desde minha entrada há quase três lustros.

Ao Prof. Dr. Eder C.R. Quintão, reconhecido pesquisador $e$ cientista cativante, por quem tive o privilégio de ser orientado no Mestrado e agora no Doutorado.

Ao Dr. Aytan Miranda Sipahi, meu amigo, que derramou sobre esta tese sua frondosa erudição e seu inefável amor à ciência.

À Profa. Dra. Angelita Habr-Gama, minha grande incentivadora, pelo constante reconhecimento profissional a mim dedicado.

Ao Prof. Dr. Giovanni G. Cerri, chefe do Setor de Ultrasonografia do Instituto do Coração do HCFMUSP, pela preciosa ajuda na elaboração e execução desta tese.

À Dra. Denise Paranaguá Vezozzo, incansável colaboradora, pela inestimável contribuição na realização dos exames ultra-sonográficos.

A meus colegas, Dra. Patrícia L. Gonçalves, Dr. Adelmário A.S. Bastos, Dr. Alberto Q. Farias, Dra. Magaly G. Teixeira e Dr. Carlos Brunetti, por terem tornado possivel a concretização deste trabalho através do recrutamento e encaminhamento dos pacientes, além da participação no exame ultra-sonográfico.

Aos estatísticos Júlia Tizue Fukushima e Pedro Fukui pelo valioso auxílio especializado e pela invejável capacidade, clareza, objetividade e, acima de tudo, paciência com que abordam esse tema. 
À Seção de Dietética Experimental da Divisão de Nutrição e Dietética do HCFMUSP, pelo convívio agradável e pela incomensurável colaboração de sua diretora, Dra. Janete Maculevicius e das nutricionistas: Marijara de Souza Leite, Yara Carnevalli Baxter, Roseli Borghi, Emília Y. Ishimoto, Maria Carolina G. Dias e Ana Lúcia Neves Duarte.

Aos professores, assistentes, residentes, estagiários e funcionários do Departamento de Gastrenterologia da FMUSP e do Laboratório de Investigação Médica em Gastrenterologia (LIM 07) pelo coleguismo e encorajamento.

Aos membros da Biblioteca da FMUSP pela permanente atenção e costumeira gentileza.

À Fundação Coordenação de Aperfeiçoamento de Pessoal de Nivel Superior (CAPES) pela bolsa de estudos a mim concedida.

A todos que, de uma forma ou de outra, permitiram-me vencer as dificuldades inerentes a qualquer trabalho cientifico. 


\section{SUMÁRIO}

Resumo

1

1.1

1.2

2

2.1

2.2

2.3

2.3.1

2.3.2

2.3.2.1

2.3.2.2

2.3.2.3

2.3.2.4

2.3.2.5

2.3.2.6

3

3.1

3.2

3.3

3.3.1

INTRODUÇÃO 1

Fisiologia da contração da vesícula biliar ..................................1

Relação entre contração da vesícula biliar e litíase biliar ....... 6

CASUÍSTICA E MÉTODOS 12

Métodos ultra-sonográficos para avaliação do esvaziamento da vesícula biliar e gástrico. 15 Avaliação da extensão do envolvimento colônico e da atividade inflamatória da doença nos pacientes com retocolite ulcerativa inespecífica sem colectomia. .20 Análise estatística .22

Estatísticas descritivas e probabilidade de significância .22 Métodos estatísticos .24 Tabelas de contingência - Teste qui-quadrado....... 24 Análise de variância ..........................................................24 Análise de covariância .................................................... 25 Coeficiente de correlação linear ................................ 25 Análise de perfil ............................................................... 26 Análise de regressão ......................................................26

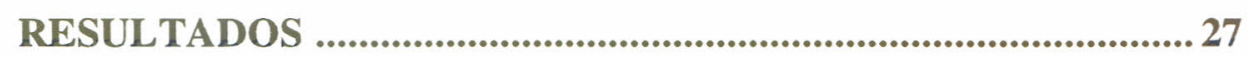

Idade, sexo e peso corpóreo relativo ......................................... 27 Esvaziamento gástrico ................................................................. 29

Esvaziamento vesicular ........................................................29

Avaliação da reprodutibilidade do método ultra-sonográfico para estudo do esvaziamento vesicular 35 
Influência do tempo de início dos sintomas, do diagnóstico, da cirurgia e da freqüência diária de evacuações póscirurgia sobre o esvaziamento vesicular 35

3.3.3 Influência da extensão da retocolite ulcerativa inespecífica sobre o esvaziamento vesicular ....................................... 38

3.3.4 Influência da atividade inflamatória da retocolite ulcerativa inespecífica sobre 0 esvaziamento vesicular ................... 38

3.3.5 Influência do consumo de medicamentos sobre o esvaziamento vesicular 40

3.3.6 Influência da presença de manifestações extra-intestinais sobre o esvaziamento vesicular ................................... 40

\section{Summary}




\section{Resumo}

Pacientes com retocolite ulcerativa inespecífica, quando submetidos à colectomia, apresentam aumento na freqüência de cálculos vesiculares de colesterol. A hipomotilidade da vesícula biliar tem sido apontada como um importante fator na formação dos cálculos vesiculares de colesterol, ao lado da supersaturação biliar de colesterol e da nucleação dos cristais de colesterol (fatores nucleantes e antinucleantes). A estase vesicular aumenta o tempo de reabsorção de água pela mucosa da vesícula biliar com conseqüente superconcentração dos solutos, além de gerar o tempo necessário para a nucleação do colesterol, retenção e fusão dos cristais e, finalmente, formação dos cálculos. Embora a composição biliar já tenha sido estudada em pacientes colectomizados, não há informações sobre o comportamento da motilidade da vesícula biliar em pacientes com retocolite ulcerativa inespecífica com e sem colectomia. No presente trabalho, o esvaziamento vesicular foi estudado através do método ultra-sonográfico e após ingestão de dieta líqüida gordurosa em indivíduos controles $(n=40)$, pacientes com retocolite ulcerativa inespecífica sem ( $\mathrm{n}$ $=30)$ e com colectomia $(n=20)$. Como o esvaziamento gástrico pode interferir no vesicular, o tempo de esvaziamento gástrico, medido por método ultra-sonográfico, foi calculado nos três grupos. O esvaziamento vesicular foi significantemente diminuído nos pacientes com retocolite ulcerativa inespecífica com colectomia e após estímulo alimentar; esta alteração não foi conseqüência de esvaziamento gástrico retardado pois o tempo de esvaziamento gástrico foi semelhante nos três grupos. Ademais, a redução da motilidade vesicular nos pacientes colectomizados 
relacionou-se com a colectomia propriamente dita, uma vez que indivíduos controles e pacientes com retocolite ulcerativa inespecífica sem colectomia apresentaram esvaziamentos vesiculares semelhantes. Além disso, os resultados desta investigação reforçam a relevância do papel da motilidade vesicular na colelitíase e sua participação, juntamente com a diminuição do "pool"de ácidos biliares, na patogênese da calculose vesicular de colesterol em pacientes com retocolite ulcerativa inespecífica submetidos à colectomia. 


\section{INTRODUÇÃO}

\subsection{Fisiologia da contração da vesícula biliar}

A vesícula biliar, no ser humano, é responsável pelo armazenamento e concentração da bile, elemento fundamental para a digestão e absorção da gordura alimentar e principal via de excreção do colesterol presente no organismo (1-6).

A bile secretada pelo fígado dirige-se para a vesícula biliar em função da resistência oferecida pelo esfíncter de Oddi cuja pressão, em jejum, oscila entre 12 e $15 \mathrm{~cm}$ de água (7). Sendo a pressão de abertura do ducto cístico aproximadamente 8 $\mathrm{cm}$ de água e a vesicular $10 \mathrm{~cm}$ de água, ambas menores que a gerada no esfíncter de Oddi, o gradiente pressórico que se forma favorece a entrada da bile na vesícula biliar (7-9). Nela, a absorção de água e eletrólitos faz com que os componentes lipídicos da bile (colesterol, sais biliares e lecitina) concentrem-se cerca de dez vezes $(10-14)$. 
Os mecanismos de contração da vesícula biliar são complexos e envolvem interação de agentes neurais (principalmente colinérgicos), hormonais, peptídeos gastrintestinais e vias não adrenérgicas e não colinérgicas (7,15-20).

Estudos em que indivíduos mastigavam o alimento sem degluti-lo ("sham feeding") revelaram que a vesícula biliar contrai-se e que a contração é bloqueada pela atropina (antagonista colinérgico) e vagotomia (21-25). Isto significa que a contração vesicular observada nesta fase é dependente da via colinérgica (vagal). O estímulo vagal, por sua vez, promove a liberação de hormônios (gastrina, motilina) e peptídeos gastrintestinais (bombesina, substância $\mathrm{P}$, neuropeptídeo Y), todos capazes de contrair a vesícula biliar (26-29).

A distensão antral e duodenal provocam contração vesicular através dos reflexos pilorocolecístico e enterocolecístico respectivamente, ambos mediados por fibras vagais (19,30-32). Ademais, como já mencionado, o estímulo vagal pode promover a liberação de hormônios e peptídeos gastrintestinais que contribuirão para a contração vesicular (21,26-29).

A presença do alimento no duodeno (particularmente ácidos graxos com nove ou mais carbonos e aminoácidos, principalmente triptofano e fenilalanina) estimula a liberação do hormônio colecistocinina (CCK) a partir da mucosa do intestino delgado (33-38). A CCK é produzida nas chamadas células CCK ou I, grupo de células endócrinas pertencentes ao sistema de células APUD ("Amine Precursor Uptake Decarboxylation") (26,39-41). As células I são mais numerosas na mucosa duodenal e diminuem gradualmente em direção ao íleo terminal (26). Várias formas moleculares de CCK são sintetizadas e enumeradas de acordo com a 
quantidade de aminoácidos, a saber: CCK-8, CCK-22, CCK-33, CCK-39 e CCK-58 (28). Aparentemente, só CCK-8 e CCK-33 têm importância fisiológica (19).

Com a ingestão do alimento, o nível plasmático de CCK começa a elevarse dois minutos após e alcança o nível máximo por volta de dezesseis minutos (42). As principais ações da CCK são o estímulo da contração vesicular e da secreção de enzimas pancreáticas (43-45).

A contração vesicular causada pela CCK dá-se por ação direta sobre a musculatura lisa vesicular ou indiretamente, por via neural (colinérgica) (17). A CCK interage com receptor específico (proteína de 85 a $95 \mathrm{kD}$ ) presente na superfície das células musculares lisas (46-50), resultando em modificações no seu conteúdo intracelular (ex., redução da adenosina monofosfato cíclica - AMFc, aumento do inositol trifosfato e do cálcio), que causam a contração muscular (7,17,51). Mais recentemente (17,52-58), verificou-se que a CCK pode provocar contração vesicular através de via neural, colinérgica e que esta, fisiologicamente, talvez seja mais importante que a direta acima descrita (17). Atropina diminui a resposta contrátil vesicular induzida por refeição de prova ou CCK exógena $(30,31,54,59,60)$. Portanto, a completa ação da CCK sobre a musculatura vesicular depende da integridade da via colinérgica (19). É interessante salientar que a CCK foi identificada em neurônios vagais no plexo vesicular intramural e no sistema nervoso central, podendo assim agir como um neurotransmissor (7).

Em condições normais, a contração vesicular sob estímulo da CCK é tão vigorosa que, 30 a 45 minutos após ingestão do alimento, 70 a $80 \%$ do conteúdo vesicular são expelidos para o colédoco alcançando finalmente o duodeno $(19,20)$. O 
relaxamento do esfíncter de Oddi, provocado pela CCK, também favorece o fluxo de bile para o duodeno (61-63).

Além da CCK, outros hormônios e peptídeos gastrintestinais participam do controle da contração vesicular. Sua liberação pode ocorrer por estímulo neural ou alimentar e sua ação sobre a musculatura vesicular pode ser direta (interação com receptores na musculatura lisa vesicular) ou indireta (liberação de outros peptídeos ou via neural) $(7,17,18,20,26)$. Na Tabela 1 , um elenco de peptídeos gastrintestinais é assinalado, com suas respectivas ações sobre a vesícula biliar e distribuição ao longo do trato digestivo.

Em 1993, Mourelle et al (64) descreveram uma via não adrenérgica e não colinérgica relacionada com a motilidade da vesícula biliar. Trata-se da via argininaóxido nítrico. O óxido nítrico estimula a guanilato ciclase elevando assim a guanosina monofosfato cíclica (GMFc). O acúmulo de GMFc na musculatura lisa vesicular inibe a contração muscular e o resultado final é o relaxamento vesicular. Contrariamente, a inibição da via arginina-óxido nítrico leva à contração vesicular (64). Esta mesma via também está relacionada com o controle da motilidade do esfíncter de Oddi (65).

Finalmente, vale ressaltar que a vesícula biliar, ao contrário do que se pensava no passado, contrai-se também no período interdigestivo em sincronia com o complexo motor migratório gastrintestinal, contração esta regulada por mecanismos neurais colinérgicos e pela motilina (66-74). A contração vesicular nos períodos interdigestivos contribui para impedir estase vesicular e a conseqüente precipitação do colesterol e formação de cálculos (19). 
Tabela 1 - Hormônios e peptídeos gastrintestinais e suas respectivas ações sobre a contração vesicular e distribuição ao longo do trato digestivo (referências $7,26-28$ ).

\begin{tabular}{|c|c|c|c|}
\hline ESTIMULANTES & LOCAL DE PRODUÇÃO & INIBIDORES & LOCAL DE PRODUÇÃO \\
\hline 1. COLECISTOCININA & INTESTINO DELGADO & $\begin{array}{l}\text { 1. POLIPEPTÍDEO } \\
\text { INTESTINAL }\end{array}$ & $\begin{array}{l}\text { TRATO GASTRINTESTINAL E } \\
\text { PÂNCREAS }\end{array}$ \\
\hline 2. GASTRINA & ESTÔMAGO & VASOATIVO & \\
\hline 3. SECRETINA & INTESTINO DELGADO & 2. SOMATOSTATINA & $\begin{array}{l}\text { TRATO GASTRINTESTINAL (MAIS } \\
\text { INTESTINO DELGADO) E PÂNCREAS }\end{array}$ \\
\hline 4. MOTILINA & $\begin{array}{l}\text { TRATO GASTRINTESTINAL } \\
\text { (MAIS ESTÔMAGO E INTESTINO } \\
\text { DELGADO) }\end{array}$ & $\begin{array}{l}\text { 3. POLIPEPTÍDEO } \\
\text { PANCREÁTICO }\end{array}$ & PÂNCREAS \\
\hline 5. NEUROPEPTÍDEO Y & TRATO GASTRINTESTINAL & 4. PEPTÍDEO YY & INTESTINO DELGADO E GROSSO \\
\hline 6. SUBSTÂNCIA P & $\begin{array}{l}\text { TRATO GASTRINTESTINAL } \\
\text { (MAIS INTESTINO DELGADO) }\end{array}$ & $\begin{array}{l}\text { 5. PEPTÍDEO RELACIO- } \\
\text { NADO C/ CALCITONINA }\end{array}$ & $\begin{array}{l}\text { TRATO GASTRINTESTINAL E } \\
\text { PÂNCREAS }\end{array}$ \\
\hline 7. BOMBESINA & $\begin{array}{l}\text { TRATO GASTRINTESTINAL E } \\
\text { PÂNCREAS }\end{array}$ & 6. PANCREASTATINA & $\begin{array}{l}\text { PÂNCREAS E TRATO } \\
\text { GASTRINTESTINAL }\end{array}$ \\
\hline 8. HISTAMINA* & $\begin{array}{l}\text { ESTÔMAGO E INTESTINO } \\
\text { DELGADO }\end{array}$ & 7. NEUROTENSINA & $\begin{array}{l}\text { TRATO GASTRINTESTINAL (MAIS } \\
\text { INTESTINO DELGADO) }\end{array}$ \\
\hline & & 8. HISTAMINA* & ESTÔMAGO E INTESTINO DELGADO \\
\hline
\end{tabular}

* Promove contração através de receptores $\mathrm{H} 1$ e relaxamento através de receptores $\mathrm{H} 2$ 


\subsection{Relação entre contração da vesícula biliar e litíase biliar}

Até os anos 70, a etiopatogênese da colelitíase de colesterol apoiava-se somente na supersaturação biliar de colesterol (75-77). A verificação de que indivíduos normais podiam apresentar bile supersaturada de colesterol mas sem cálculos (78-83), ensejou uma pesquisa mais abrangente que também inclui: a) agentes pró e antinucleantes que interferem no processo de nucleação e formação dos cristais de colesterol (78-83); b) motilidade da vesícula biliar, responsável pelo "clearance" do conteúdo vesicular (84-87). Esta visão mais ampla deve-se, basicamente, a três fatores. Em primeiro lugar à descoberta de que o colesterol biliar é, em grande parte, transportado sob a forma de vesículas unilamelares, de diâmetro de 40 a $80 \mathrm{~nm}$, compostas de uma bicamada de colesterol e fosfolípides (88-92); em condições de supersaturação biliar de colesterol, as vesículas fundem-se gerando cristais de colesterol (93-95). Em segundo lugar, à constatação de que existem agentes que favorecem a formação dos cristais de colesterol (ex., mucina, cálcio) e outros que a inibem (ex., apolipoproteínas $A_{1}$ e $A_{2}$ ) (96). Em terceiro lugar, à importância da hipomotilidade ou estase vesicular na geração do ambiente e tempo favoráveis para coalescência das vesículas unilamelares, nucleação e agregação dos cristais de colesterol e, finalmente, desenvolvimento dos cálculos $(7,20,85)$. 
Estudos controlados têm revelado que cerca de $50 \%$ dos pacientes portadores de colelitíase de colesterol têm esvaziamento vesicular diminuído (Tabela 2), quer com estímulo exógeno (CCK), quer com endógeno (refeição de prova) (97122).

Em modelos experimentais de calculose de colesterol, como é o caso da marmota, que desenvolve litíase com dieta rica em colesterol, a hipomotilidade vesicular, constatada por método cintilográfico, ocorreu precocemente e precedeu a formação dos cálculos (123-129). Nestes mesmos animais, injeções intramusculares de CCK reduziram a freqüência de calculose biliar (130). Em pacientes com cristais de colesterol na vesícula biliar, porém sem cálculos, a fração de ejeção vesicular, medida por método cintilográfico, foi $26 \%$ enquanto nos controles foi $60 \%$ (131). Além disso, a associação de inibidor da tripsina (FOY-305) (aumenta a liberação duodenal de CCK e a contração vesicular) com o ácido ursodeoxicólico facilitou ainda mais a dissolução de cálculos de colesterol (132).

Condições reconhecidamente associadas com maior freqüência de litíase biliar têm na estase vesicular uma das explicações para a sua etiopatogênese. É o caso do jejum prolongado $(94,95,133)$, nutrição parenteral total prolongada (134-140), lesão medular espinhal (141-142), gravidez (143-146), uso de anticoncepcionais (146151), obesidade e perda rápida de peso (152-156), diabetes mellitus (157-160), vagotomia $(7,20,54)$, tratamento com somatostatina (ou seu análogo octreotide), tumor secretor de somatostatina (somatostatinoma) (161-166), anemia falciforme (167), doença de Crohn $(168,169)$ e gastrectomia Billroth II $(170,171)$. 
Tabela 2 - Relação dos trabalhos controlados sobre esvaziamento vesicular que revelaram hipomotilidade vesicular em pacientes com colelitíase de colesterol.

\begin{tabular}{|c|c|c|c|c|c|}
\hline $\begin{array}{c}\text { Autores } \\
\text { (referências) }\end{array}$ & Ano & $\begin{array}{c}\text { Número de pacientes } \\
\text { com litf́ase }\end{array}$ & $\begin{array}{l}\text { Método de estudo do } \\
\text { esvaziamento vesicular }\end{array}$ & $\begin{array}{c}\text { Estímulo para } \\
\text { contração vesicular }\end{array}$ & $\begin{array}{c}\% \text { pacientes com } \\
\text { hipomotilidade vesicular }\end{array}$ \\
\hline 1. Shaffer et al (97) & 1980 & 7 & Cintilografia & CCK *1 & 85 \\
\hline 2. Thompson et al (98) & 1982 & 24 & Ultra-som & Refeição & 42 \\
\hline 3. Bobba et al (99) & 1982 & 7 & Cintilografia & Refeição & Em média, diminuída *2 \\
\hline 4. Mesgarzadeh et al (101) & 1982 & 9 & Cintilografia & CCK & Em média, diminuída \\
\hline 5. Fisher et al (103) & 1982 & 15 & Cintilografia & Refeição & Em média, diminuída \\
\hline 6. Forgacs et al (104) & 1984 & 39 & Cintilografia e Ultra-som & CCK & Em média, diminuída \\
\hline 7. Pomeranz e Shaffer (105) & 1985 & 26 & Cintilografia & CCK & 42 \\
\hline 8. Kishk et al (106) & 1987 & 20 & Ultra-som & Refeição & 70 \\
\hline 9. Upp et al (107) & 1987 & 23 & Ultra-som & Refeição & 43 \\
\hline 10. Sylwestrowicz e Shaffer (108) & 1988 & 37 & Cintilografia & CCK & 54 \\
\hline 11. Spengler et al (109) & 1989 & 21 & Ultra-som & CCK & Em média, diminuída \\
\hline 12. Masclee et al (110) & 1989 & 20 & Cintilografia & Infusão duodenal & Em média, diminuída \\
\hline 13. Legmann et al (111) & 1989 & 35 & Ultra-som & Refeição e/ou CCK & Em média, diminuída \\
\hline 14. Festi et al (112) & 1990 & 75 & Ultra-som & Refeição & Em média, diminuída \\
\hline 15. Van Erpecum et al (113) & 1992 & 20 & Ultra-som & Refeição & 35 \\
\hline 16. Palasciano et al (114) & 1992 & 108 & Ultra-som & -- & $\begin{array}{l}\text { Só analisou volume de jejum } \\
\text { (Em média, aumentado) }\end{array}$ \\
\hline 17. Catnach et al (115) & 1992 & 13 & Ultra-som & Refeição & 62 \\
\hline 18. Pauletzki et al (117) & 1993 & 56 & Ultra-som & Refeição & 23 \\
\hline 19. Portincasa et al (118) & 1994 & 150 & Ultra-som & Refeição & 28 \\
\hline 20. Portincasa et al (119) & 1994 & 36 & Ultra-som & Refeição & 47 \\
\hline 21. Berr et al (120) & 1994 & 10 & Ultra-som & CCK & Em média, diminuída \\
\hline 22. Pauletzki et al (121) & 1995 & 21 & Ultra-som & CCK & Em média, diminuída \\
\hline 23. Shoda et al (122) & 1995 & 32 & Ultra-som & Ceruleína & Em média, diminuída \\
\hline
\end{tabular}

*1 Colecistocinina

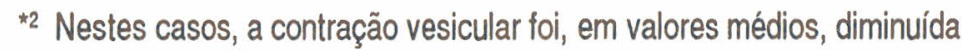


Os mecanismos envolvidos na alteração da contração vesicular nos pacientes com litíase de colesterol não estão totalmente elucidados (7). Não parece depender da presença do cálculo e, até certo ponto, da inflamação vesicular $(105,107,112,113,118,172)$. Mesmo após a litotripsia extracorpórea e desaparecimento dos cálculos, a hipomotilidade vesicular persiste $(109,173)$. Semelhantemente, a falta de sucesso terapêutico na litotripsia extracorpórea está relacionada com hipomotilidade vesicular prévia ao tratamento (120,174-176). Todavia, a hipomotilidade vesicular pode relacionar-se com a supersaturação biliar de colesterol $(96,123-129,177)$. Behar et al (178), estudando a contração muscular vesicular in vitro de pacientes colecistectomizados por cálculos pigmentares ou de colesterol, observaram que a resposta contrátil foi menor no grupo com cálculos de colesterol. Dados semelhantes foram observados em pacientes com cristais de colesterol na vesícula biliar (mas sem cálculos) (131), na colesterolose $(77,86,178)$ e em estudos experimentais in vivo (123-129). Sabe-se que alterações no conteúdo de colesterol da membrana celular podem interferir nas funções celulares $(17,179)$. Assim, o colesterol, excessivamente absorvido pela mucosa vesicular, poderia afetar o processo de contração vesicular através de alterações na composição lipídica (aumento da relação colesterol: fosfolípides) da membrana celular da célula epitelial e/ou do músculo liso com conseqüente prejuízo das funções de receptores, proteínas contráteis e da mobilização do cálcio intracelular (17,51).

Por outro lado, os trabalhos seqüenciais de Thompson et al $(98,107)$ revelaram que pacientes litiásicos com hipomotilidade vesicular apresentavam diminuição do número de receptores para CCK na musculatura lisa da vesícula biliar, 
o mesmo acontecendo em animais de experimentação (180). A concentração de CCK na mucosa duodenal mostrou-se aumentada em pacientes com colelitíase e Tierney et al (7) sugeriram que isto ocorreria para compensar a redução do número de receptores vesiculares para CCK. Além disso, Masclee et al (110) descreveram um subgrupo de pacientes com colelitíase com secreção duodenal de CCK reduzida após estímulo endógeno.

Nesta mesma linha envolvendo receptores, Daignault et al (181) demonstraram que pacientes litiásicos com hipomotilidade vesicular apresentavam receptores para progesterona na vesícula biliar, enquanto que naqueles com motilidade normal tais receptores não foram identificados. A progesterona é um potente relaxante da musculatura lisa vesicular $(149,182)$, bem como dos intestinos, vasos sangüíneos, ureteres e útero (149).

Recentemente, a bile de pacientes colectomizados por retocolite ulcerativa inespecífica (RCUI) foi estudada (183) numa tentativa de esclarecer a maior frequiência de cálculos vesiculares de colesterol nesta população (183-185). A bile mostrou-se litogênica, com índice de saturação biliar de colesterol elevado e tempo de nucleação (tempo para aparecimento de cristais de colesterol na bile após retirada dos cálculos e cristais) reduzido (183). Embora a composição biliar já tenha sido investigada neste grupo de pacientes, não há informações sobre a motilidade vesicular em pacientes colectomizados. A estase vesicular, jamais avaliada nestes pacientes, poderia estender o tempo de reabsorção de água pela mucosa da vesícula biliar com conseqüente superconcentração dos solutos, além de gerar o tempo necessário para a nucleação do colesterol, retenção e fusão dos cristais e, por último, formação dos cálculos $(7,20,93,94)$. 
Desta forma, no presente trabalho, avaliamos o esvaziamento vesicular por método ultra-sonográfico $(168,186,187)$ e sob estímulo endógeno (refeição padrão) em indivíduos normais e em pacientes com RCUI sem e com colectomia.

Também o esvaziamento gástrico foi analisado por técnica ultrasonográfica (188) em todos os grupos abordados, uma vez que ele pode influenciar a contração da vesícula biliar (103,189-191). 


\section{CASUÍSTICA E MÉTODOS}

O trabalho foi realizado após aprovação pelas Comissões de Ética do Hospital das Clínicas da Faculdade de Medicina da Universidade de São Paulo (HCFMUSP) e do Departamento de Gastrenterologia da FMUSP.

Três grupos de indivíduos, após consentimento, fizeram parte do presente estudo, a saber:

a) Grupo controle - constituído de indivíduos voluntários sadios, sem queixas gastrenterológicas e com exame clínico normal, sem uso de medicamentos e sem litíase biliar avaliada pela ultra-sonografia (192-193). Quarenta e dois indivíduos foram encaminhados para exame ultra-sonográfico e dois deles foram excluídos por apresentarem litíase vesicular, restando 40 indivíduos que totalizaram este grupo. Os dados referentes à idade, sexo, cor e peso corpóreo relativo estão na Tabela 3;

b) Grupo retocolite ulcerativa inespecífica sem colectomia (RCUI sem colectomia) - formado de pacientes atendidos no Grupo de Intestino da Disciplina de Gastrenterologia Clínica da FMUSP. O diagnóstico de RCUI foi estabelecido com base nos dados clínicos. endoscópicos e/ou radiológicos, além das biópsias colônicas e/ou retais que, em algum momento da evolução da doença, revelaram sinais de 
Tabela 3 - Características dos três grupos estudados ( $n$, idade, sexo, raça, peso corpóreo relativo). Dados expressos em média \pm EPM (erro padrão da média). $\mathrm{RCUI}=$ retocolite ulcerativa inespecífica.

\begin{tabular}{|c|c|c|c|c|c|c|c|}
\hline \multirow[t]{2}{*}{ Grupos } & \multirow[t]{2}{*}{$\mathbf{n}$} & \multirow[t]{2}{*}{ Idade (anos) } & \multicolumn{2}{|c|}{ Sexo } & \multicolumn{2}{|l|}{ Raça } & \multirow[t]{2}{*}{ Peso corpóreo relativo (\%)* } \\
\hline & & & $\begin{array}{l}\text { Homens } \\
\text { (n) }\end{array}$ & $\begin{array}{l}\text { Mulheres } \\
(n)\end{array}$ & $\begin{array}{c}\text { Caucasiana } \\
\text { (n) }\end{array}$ & $\begin{array}{l}\text { Negra } \\
\text { (n) }\end{array}$ & \\
\hline Controle & 40 & $34,0 \pm 1,5$ & 19 & 21 & 31 & 9 & $97,0 \pm 0,8$ \\
\hline \multicolumn{8}{|l|}{ RCUI sem } \\
\hline colectomia & 30 & $40,1 \pm 2,1$ & 9 & 21 & 25 & 5 & $98,4 \pm 1,5$ \\
\hline \multicolumn{8}{|l|}{ RCUI com } \\
\hline colectomia & 20 & $36,1 \pm 2,0$ & 13 & 7 & 20 & - & $97,9 \pm 2,1$ \\
\hline
\end{tabular}

${ }^{*}$ Peso corpóreo relativo $(\%)=\frac{\text { Peso }(\mathrm{Kg})}{\text { Altura }(\mathrm{cm})-100} \times 100 \%$ 
RCUI em atividade como infiltrado inflamatório agudo na mucosa, perda da arquitetura das criptas, criptite, abscessos de cripta, depleção de células caliciformes, congestão, edema, hemorragias focais e ulcerações (194-197). Outras causas de colite como infecções, parasitoses, radiação e isquemia foram descartadas através da história clínica e evolução do quadro, exames de fezes, coproculturas e, quando necessário, provas sorológicas (196). Trinta e dois pacientes foram convocados para realização do exame ultra-sonográfico. Dois deles foram retirados do estudo por apresentarem litíase vesicular, restando 30 pacientes que compuseram o grupo. Todos os pacientes vinham sendo atendidos em regime ambulatorial. As características do grupo encontram-se na Tabela 3;

c) Grupo retocolite ulcerativa inespecífica com colectomia (RCUI com colectomia) - integraram este grupo pacientes portadores de RCUI e que foram submetidos à colectomia na Disciplina de Cirurgia do Aparelho Digestivo da FMUSP. Vinte e dois pacientes foram recrutados para exame ultra-sonográfico e dois deles não foram incluídos no grupo por apresentarem litíase vesicular. Dos 20 restantes, 14 haviam sido submetidos à reconstrução do trânsito através de anastomose ileoanal com bolsa ileal ("pouch") em J, 3 à bolsa ileal em J mais ileostomia em alça, 2 à ileostomia e 1 à íleo-reto anastomose (198-203). Em 12 pacientes a colectomia foi indicada por falência do tratamento clínico, em 6 por enterorragia grave, em 1 por megacólon tóxico e em 1 por pioderma gangrenoso. O diagnóstico de RCUI, em todos os casos, foi confirmado através do estudo anatomopatológico da peça cirúrgica. Em todos os casos, menos de $5 \mathrm{~cm}$ de íleo terminal foram ressecados. Nenhum paciente apresentava sangue nas fezes ou dor abdominal e todos vinham sendo acompanhados ambulatorialmente (Tabela 3). 


\subsection{Métodos ultra-sonográficos para avaliação do esvaziamento da vesícula biliar e gástrico}

Após 8 horas de jejum, todos os indivíduos compareceram ao Setor de Ultra-sonografia do Instituto do Coração do HCFMUSP para realização do exame ultra-sonográfico abdominal (Aparelho Toshiba - Sonolayer SSA - 250A, transdutor convexo de $3.75 \mathrm{MHz}$ ).

Antes do exame, cada indivíduo preencheu uma ficha de identificação (Anexo A, Figuras 1,2,3). Nos pacientes dos grupos RCUI sem colectomia e RCUI com colectomia, além da identificação, foram acrescidas informações sobre tempo decorrido entre início dos sintomas e diagnóstico de RCUI e a data do exame ultrasonográfico, tempo decorrido entre o tratamento cirúrgico (colectomia) e a data do exame ultra-sonográfico, tipo de cirurgia, complicações da doença (incluindo manifestações extra-intestinais), uso de medicamentos e quadro clínico atual (incluindo número de evacuações diárias) (Anexo B, Tabelas 1,2,3,4).

O estudo do esvaziamento da vesícula biliar foi feito seguindo-se o método ultra-sonográfico descrito por Dodds et al (186) e adaptado por Murray et al (168), denominado método elipsóide. Por este método, com o indivíduo em ortostase, são obtidos os seguintes cortes para coleta das medidas vesiculares: a) corte sagital, para medida do maior eixo longitudinal correspondente ao comprimento vesicular 
(Figura 1A); b) corte axial ou transversal para medida da largura e altura vesiculares (Figura 1B). O volume vesicular é finalmente dado pela fórmula:

$$
\mathrm{V}=\frac{\pi}{6}(\mathrm{C} \times \mathrm{L} \times \mathrm{A})
$$

A letra $\mathrm{V}$ representa o volume vesicular em $\mathrm{ml} ; \pi / 6$ é uma constante que equivale a 0,$52 ; \mathrm{C}$ corresponde ao comprimento da vesícula em $\mathrm{cm}$; $\mathrm{L}$ é a largura da vesícula biliar em cm; A é a altura ou profundidade ou diâmetro anteroposterior vesicular em $\mathrm{cm}$.

As primeiras medidas foram feitas em jejum. Em seguida, cada indivíduo ingeriu, diante do examinador, $300 \mathrm{ml}$ de refeição líqüida gordurosa, padrão, fornecida pela Divisão de Nutrição e Dietética do HCFMUSP e contendo $29 \mathrm{~g}$ de carboidratos, $26 \mathrm{~g}$ de gordura, $19 \mathrm{~g}$ de proteínas e $418 \mathrm{~K}$ cal (191). A seguir, como preconizado por Murray et al (168), as medidas foram realizadas a cada 10 minutos até 50 minutos.

O exame foi sempre realizado pelo mesmo médico e, para avaliação da reprodutibilidade do método, 40 indivíduos foram sorteados a partir dos três grupos e, sem conhecimento do examinador, realizaram duas medidas em jejum, com espaço também de 10 minutos.

A curva de esvaziamento vesicular foi delineada convertendo-se os volumes vesiculares em porcentagem do volume vesicular de jejum ou inicial de acordo com Murray et al (168) (Anexo A, Figura 1).

Com base nas medidas vesiculares, foram calculados os seguintes parâmetros de acordo com Sood et al (204): a) volume (ml) vesicular de jejum (VVJ); b) volume $(\mathrm{ml})$ vesicular residual mínimo (VVRM), correspondente ao menor 


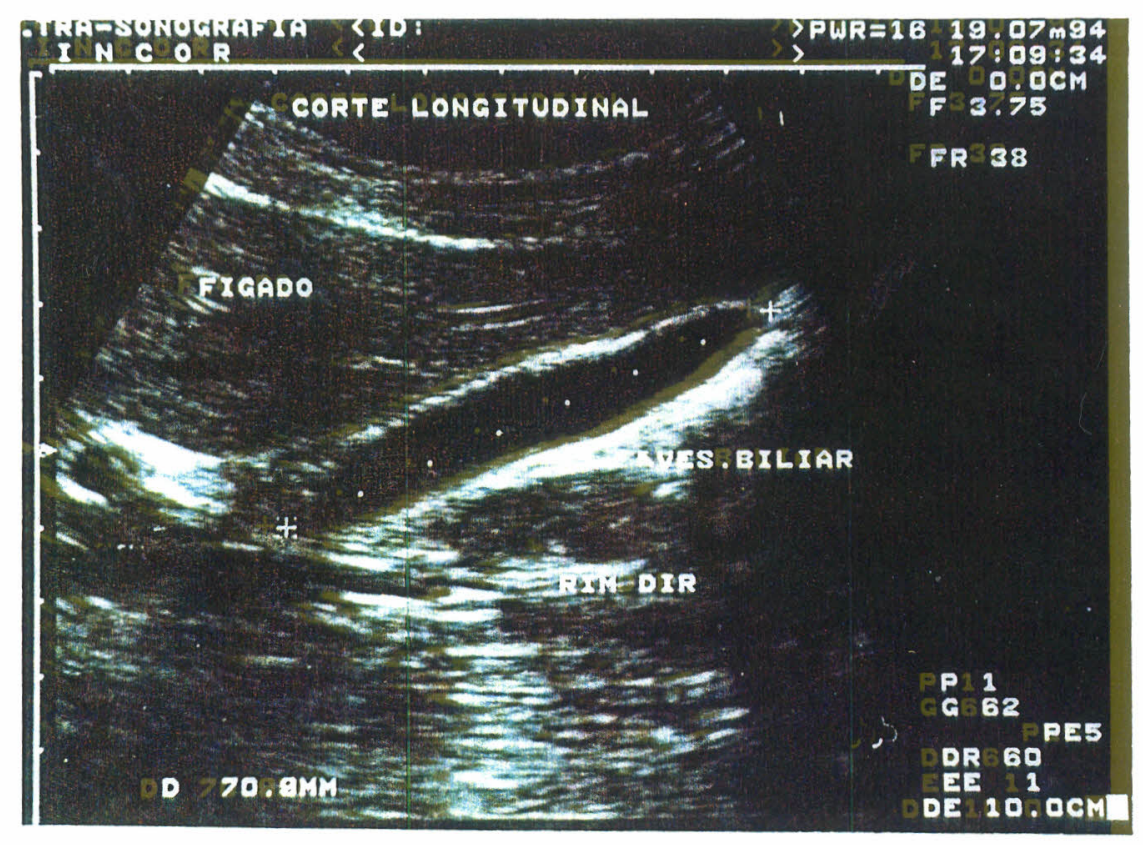

A

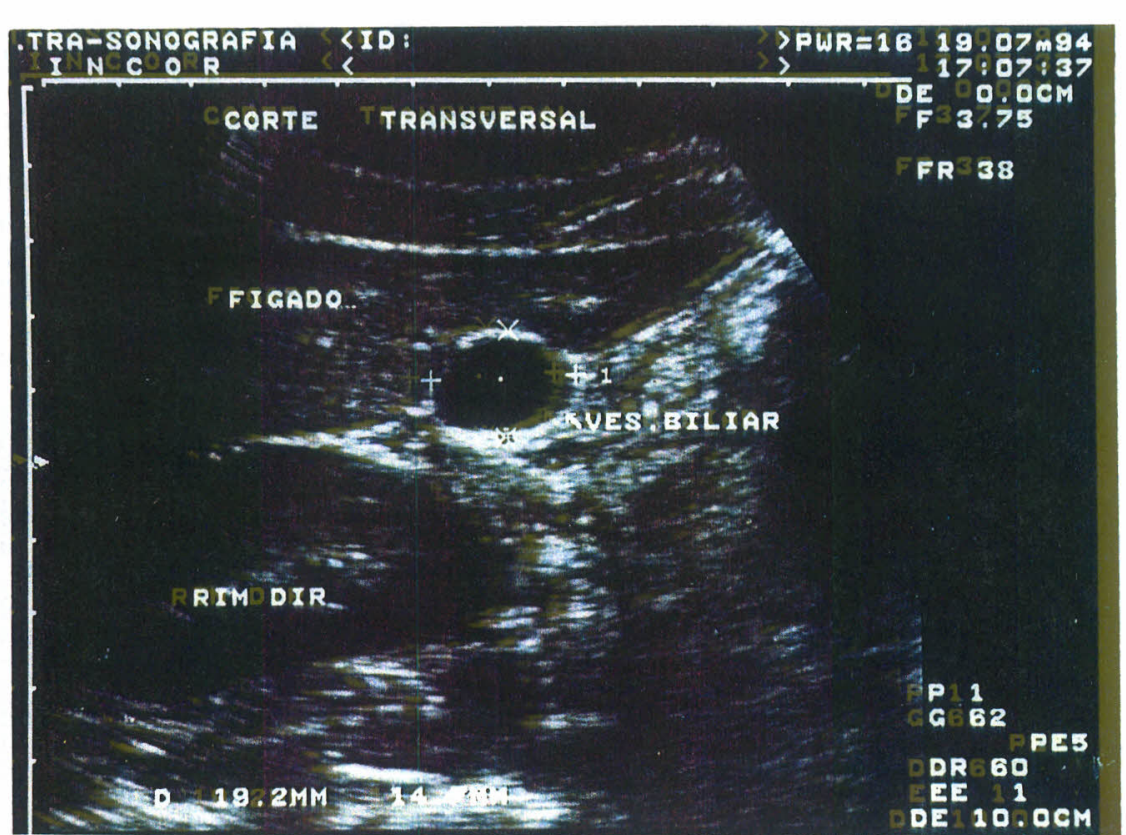

B

Figura 1 - Ultra-sonografia da vesícula biliar. Indivíduo em ortostase. $A=$ Corte sagital, para medida do maior eixo longitudinal correspondente ao comprimento vesicular (+---------+); B = Corte axial ou transversal para medida da largura (+---------+) e profundidade (X---------X) vesiculares. 
volume vesicular detectado durante o exame; c) diferença $(\mathrm{ml})$ entre o volume vesicular de jejum e o volume vesicular residual mínimo ( $\Delta$ VVJ-VVRM), que equivale ao volume de bile que efetivamente foi esvaziado da vesícula biliar; d) porcentagem máxima de esvaziamento vesicular (PMEV), que é a expressão do $\Delta$ VVJ-VVRM em porcentagem; e) tempo (minutos) decorrido para contração máxima vesicular (TCMV).

Em 10 indivíduos de cada grupo o tempo de esvaziamento gástrico foi estudado além da prova motora vesicular. O tempo de esvaziamento gástrico foi calculado através do método ultra-sonográfico proposto por Bolondi et al (188). Segundo este método, com o indivíduo em ortostase, obtém-se um corte sagital ou longitudinal que passa pela veia mesentérica superior e antro gástrico. A área antral é calculada medindo-se os diâmetros longitudinal e anteroposterior (Figura 2) e aplicando-se a fórmula:

$$
\text { Área Antral }\left(\mathrm{cm}^{2}\right)=\frac{\pi \times \mathrm{AB}}{4}
$$

O $\pi / 4$ corresponde a uma constante igual a 0,7854 ; A é o diâmetro longitudinal $(\mathrm{cm})$; B o diâmetro anteroposterior $(\mathrm{cm})$. Para as medidas antrais, sempre foi considerado o perfil externo da parede gástrica para evitar confusão com conteúdo intraluminal. A primeira medida da área antral foi feita com o paciente em jejum (pelo menos 8 horas). A segunda medida, logo após a ingestão da refeição de prova descrita anteriormente para o estudo motor vesicular. A partir daí, a cada 15 minutos até esvaziamento completo do estômago. O estômago foi considerado vazio quando a área antral retornou à obtida em jejum e confirmada após 30 minutos 


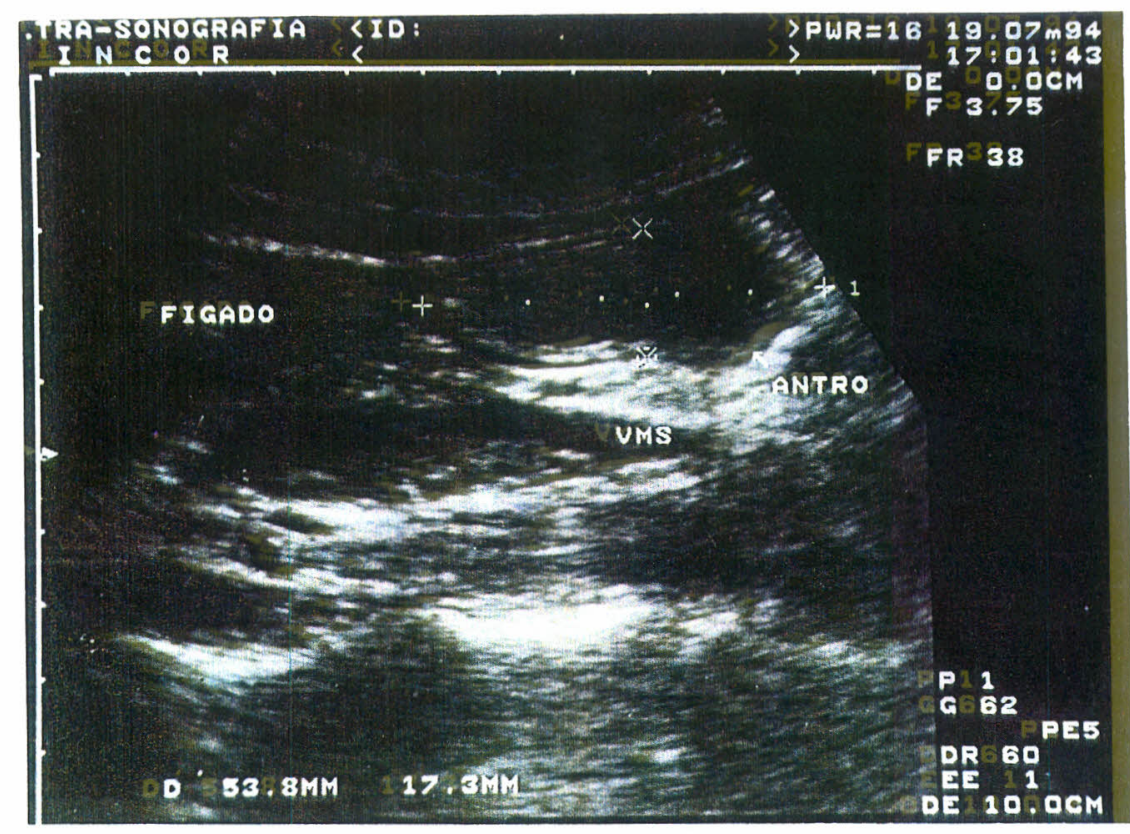

Figura 2 - Ultra-sonografia gástrica (região antral). Indivíduo em ortostase. Corte sagital passando pela veia mesentérica superior (VMS)

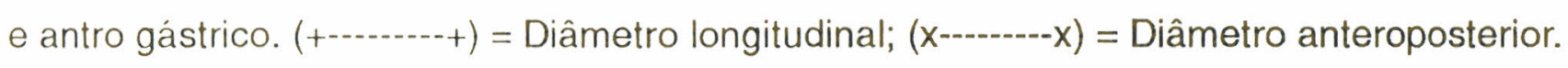


(Anexo A, Figura 4). O tempo de esvaziamento gástrico foi calculado em relação ao início da ingestão da refeição de prova (188).

\subsection{Avaliação da extensão do envolvimento colônico e da atividade inflamatória da doença nos pacientes com RCUI sem colectomia}

A extensão anatômica do processo inflamatório no grupo RCUI sem colectomia foi avaliada através da colonoscopia e de acordo com Farmer (205). Na Tabela 4 são descritas as três formas de RCUI no que diz respeito à extensão do envolvimento colônico (RCUI distal, RCUI do hemicólon esquerdo e RCUI extensa) e a divisão do grupo de acordo com esta extensão.

A atividade inflamatória da doença foi analisada utilizando-se critérios clínicos e laboratoriais (196).

O índice de atividade (IA) de Seo et al (206), que leva em conta parâmetros clínicos e laboratoriais, foi calculado para cada paciente na época do exame ultra-sonográfico (Anexo B, Tabela 5). Tal índice baseia-se em dados clínicos (presença de sangue nas fezes, número de evacuações/dia) e laboratoriais (velocidade de hemossedimentação, hemoglobina e albumina séricas) cujos resultados são colocados na fórmula:

$\mathrm{IA}(\mathrm{RCUI})=60 \mathrm{x}$ sangue nas fezes $+0,5 \times \mathrm{VHS}+13 \times \mathrm{n} \underline{\mathrm{O}}$ evacuações/dia

$$
-4 \times \mathrm{Hb}-15 \times \text { Albumina }+200
$$


Tabela 4 - Características dos pacientes do grupo retocolite ulcerativa inespecífica (RCUI) sem colectomia quanto à extensão do processo inflamatório.

RCUI distal

10

RCUI hemicólon esquerdo 5

RCUI extensa

15

Total

30

* De acordo com Farmer, 1987 (referência 205):

RCUI DISTAL

Proctite - inflamação da mucosa retal até $15 \mathrm{~cm}$ da linha denteada

Proctossigmoidite - inflamação da mucosa até $25-30 \mathrm{~cm}$ da linha denteada

RCUI HEMICÓLON ESQUERDO

Inflamação da mucosa até a flexura esplênica (eventualmente, até o cólon transverso distal)

RCUI EXTENSA

Inflamação da mucosa estendendo-se além do cólon transverso distal (geralmente além da flexura hepática) 
O "sangue nas fezes" é substituído por um sistema de pontuação ("scores") que considera a presença ou ausência de sangramento via retal; a velocidade de hemossedimentação (VHS) é expressa em mm, 1a h; o "nㅡㅡ de evacuações/dia" é também substituído por sistema de pontuação de acordo com a freqüência diária de evacuações; o valor da hemoglobina $(\mathrm{Hb})$ é expresso em $\mathrm{g} / \mathrm{dl}$ assim como a albumina sérica (Anexo B, Tabela 5).

Na época do exame ultra-sonográfico foi colhido sangue dos pacientes do grupo RCUI sem colectomia e encaminhado para o Laboratório Central do HCFMUSP para realização dos seguintes exames: dosagem de hemoglobina (g/dl), contagem de leucócitos ( $\mathrm{n} \underline{\mathrm{O}}$ de leucócitos $/ \mathrm{mm}^{3}$ ) e de plaquetas ( $\mathrm{n} \underline{\mathrm{O}}$ de plaquetas $\left./ \mathrm{mm}^{3}\right)$, quantificação das mucoproteínas $(\mathrm{mg} / \mathrm{dl})$ e da albumina $(\mathrm{g} / \mathrm{dl})$ e velocidade de hemossedimentação (mm, 1a h). Na Tabela 5 estão os valores referentes ao índice de atividade inflamatória e aos exames laboratoriais.

\subsection{Análise estatística}

\subsubsection{Estatísticas descritivas e probabilidade de significância}

As estatísticas descritivas utilizadas no trabalho foram média e erro padrão da média. Os valores de $\mathrm{p}<0,05$ foram considerados estatisticamente significantes. 
Tabela 5 - Valores referentes ao índice de atividade inflamatória (IA) e às dosagens de hemoglobina, contagens de leucócitos e plaquetas, quantificação sérica das mucoproteínas e albumina e velocidade de hemossedimentação (VHS). Resultados estão expressos em média \pm EPM (erro padrão da média). Valores normais: Hemoglobina: 12 - $16 \mathrm{~g} / \mathrm{dl}$; Leucócitos: 5.000 - 10.000 leucócitos/mm3; Plaquetas: 150.000 - 400.000 plaquetas/mm3; Mucoproteínas: 2,3 - 3,6 mg/dl; VHS: homens, 0 - $10 \mathrm{~mm}$, $1^{\text {a }} \mathrm{h}$ e mulheres, 0-20 mm, 1 $\mathrm{h}$; Albumina: $3,5-5,0 \mathrm{~g} / \mathrm{dl}$.

\section{Grupo n IA* Hemoglobina Leucócitos Plaquetas Mucoproteínas VHS Albumina}

\section{RCUI sem}

colectomia

* Calculado de acordo com Seo et al, 1992 (206): IA (RCUI) $=60 \times$ sangue nas fezes + 0,5 x VHS + $13 \times$ nํevacuações/ dia -4 x Hemoglobina - 15 x Albumina +200 


\subsubsection{Métodos estatísticos}

\subsubsection{Tabela de contingência - Teste qui-quadrado}

O teste qui-quadrado de Pearson (207) foi utilizado para análise comparativa, nos três grupos, das variáveis relacionadas com sexo (masculino e feminino). Em caso de significância, prosseguiu-se a análise com a partição ou desmembramento da estatística do qui-quadrado (208).

\subsubsection{Análise de variância}

A análise de variância (209) foi empregada para comparação dos seguintes dados: a) nos três grupos: idade, peso corpóreo relativo, volume vesicular de jejum (VVJ), volume vesicular residual mínimo (VVRM), diferença entre VVJ e VVRM ( $\triangle$ VVJ - VVRM), porcentagem máxima de esvaziamento vesicular (PMEV), tempo para contração máxima vesicular (TCMV) e tempo de esvaziamento gástrico; as variáveis VVJ, VVRM e $\triangle$ VVJ-VVRM sofreram transformação logarítmica para que houvesse aproximação para a distribuição normal (curva de Gauss); nos casos em que a análise de variância detectou diferença estatisticamente significante ( $\mathrm{p}<0,05)$, o teste de Tukey (209) foi aplicado para discriminação das diferenças; b) 
nos grupos RCUI sem e com colectomia: efeito do consumo de medicamentos sobre a PMEV; c) no grupo RCUI sem colectomia: efeitos da extensão da doença e da atividade inflamatória sobre a PMEV.

\subsubsection{Análise de covariância}

A análise de covariância (210) foi utilizada para estudo da influência do sexo e idade sobre a PMEV nos três grupos.

\subsubsection{Coeficiente de correlação linear}

No grupo RCUI com colectomia, a correlação linear entre PMEV freqüência diária de evacuações na época do exame ultra-sonográfico foi avaliada pelo método não paramétrico de Spearman (211).

Nos grupos RCUI sem e com colectomia, o método de correlação de Pearson (211) foi usado para testar a correlação linear entre PMEV e tempo de início dos sintomas e diagnóstico de RCUI. Também, por este método, no grupo RCUI com colectomia, foi estudada a correlação linear entre PMEV e tempo decorrido entre a operação (colectomia) e a data do exame ultra-sonográfico. 


\subsubsection{Análise de perfil}

O comportamento das curvas de esvaziamento vesicular, nos três grupos, foi investigado através do método de análise de perfil (210). Nesta análise, três hipóteses são formuladas:

a) Hipótese 1: existe paralelismo entre as curvas, ou seja, o comportamento do perfil de médias das curvas de esvaziamento vesicular, ao longo do tempo, é semelhante nos três grupos estudados.

b) Hipótese 2: há coincidência entre os perfis de médias das curvas de esvaziamento vesicular dos três grupos.

c) Hipótese 3: não há alteração do volume vesicular ao longo do tempo, isto é, o esvaziamento é constante ao longo do tempo.

Quando $\mathrm{p}<0,05$ a hipótese aventada é rejeitada e quando $\mathrm{p}>0,05$ a hipótese é então aceita.

\subsubsection{Análise de regressão}

A reprodutibilidade do exame ultra-sonográfico foi testada através da análise de regressão (211), considerando-se os dois valores do VVJ obtidos numa mesma pessoa. O método é considerado reprodutível se a reta estimada tiver coeficiente angular próximo de 1 e interceptar o eixo das coordenadas no ponto zero. Quando $\mathrm{p}>0,05$ a hipótese de reprodutibilidade é aceita. 


\section{RESULTADOS}

\subsection{Idade, sexo e peso corpóreo}

A média de idade no grupo RCUI com coletomia foi semelhante às obtidas nos grupos controle e RCUI sem colectomia; porém,a média de idade no grupo RCUI sem colectoma foi discretamente maior que a dos controles ( $p=0,044$; Tabela 6). No entanto, a idade não influenciou o esvaziamento vesicular (análise de covariância: idade $\mathrm{x}$ PMEV, $\mathrm{p}=0,228$ ).

Não houve diferença estatisticamente significante entre a relação $\mathrm{n}^{0}$ de homens/ $\mathrm{n}^{0}$ de mulheres do grupo controle quando comparada com as dos grupos RCUI sem e com colectomia; entretanto, houve diferença entre as relações dos grupos RCUI sem e com colectomia ( $p=0,049$; Tabela 6). Tal diferença, contudo, não afetou o esvaziamento vesicular (análise de covariância: sexo $\mathrm{x}$ PMEV, $\mathrm{p}=$ 0,080).

O peso corpóreo relativo (212) foi semelhante nos três grupos analisados $(p=0,706 ;$ Tabela 6$)$. 
Tabela 6 - Idade (anos), sexo ( $0^{\zeta} \%$ = no de homens / no de mulheres) e peso corpóreo relativo (\%) nos três grupos estudados: controle, retocolite ulcerativa inespecífica (RCUI) sem e com colectomia. Valores expressos em média \pm EPM (erro padrão da média).

\begin{tabular}{|c|c|c|c|c|c|c|}
\hline \multirow[t]{2}{*}{ Grupos } & \multirow[t]{2}{*}{$\mathbf{n}$} & \multirow[t]{2}{*}{ Idade } & \multicolumn{3}{|c|}{ Sexo } & \multirow[t]{2}{*}{ Peso corpóreo relativo* } \\
\hline & & & Homens & Mulheres & 0 & \\
\hline Controle & 40 & $34,0 \pm 1,5^{\#}$ & 19 & 21 & $0,9^{4}$ & $97,0 \pm 0,8$ \\
\hline \multicolumn{7}{|l|}{ RCUI sem } \\
\hline colectomia & 30 & $40,1 \pm 2,1^{\wedge}$ & 9 & 21 & $0,4^{\#}$ & $98,4 \pm 1,5$ \\
\hline \multicolumn{7}{|l|}{ RCUI com } \\
\hline colectomia & 20 & $36,1 \pm 2,0^{\# \Delta}$ & 13 & 7 & $1,9^{4}$ & $97,9 \pm 2,1$ \\
\hline$p$ & & 0,044 & & 0,049 & & 0,706 \\
\hline
\end{tabular}

*Peso corpóreo relativo $(\%)=\frac{\text { Peso }(\mathrm{Kg})}{\text { Altura }(\mathrm{cm})-100} \times 100 \%$

Obs.: Os grupos com símbolos diferentes apresentaram diferença de médias estatisticamente significante $(p<0,05)$, em cada uma das variáveis. 


\subsection{Esvaziamento gástrico}

Os resultados do esvaziamento gástrico, incluindo os valores individuais e médios, estão na Figura 3. Não houve diferença estatisticamente significante entre os tempos de esvaziamento gástrico dos três grupos avaliados $(\mathrm{p}=0,811)$.

\subsection{Esvaziamento vesicular}

As curvas de esvaziamento vesicular, nos três grupos avaliados, encontram-se na Figura 4; as porcentagens do volume vesicular de jejum, em cada tempo, na Tabela 7. Os resultados da análise de perfil das curvas de acordo com as hipóteses testadas foram:

a) Hipótese 1: $\mathrm{p}=0,416$, o que significa dizer que o comportamento das curvas de esvaziamento vesicular, nos três grupos, foi semelhante (curvas paralelas).

b) Hipótese 2: $p=0,001$, o que significa dizer que pelo menos um dos grupos tem médias distintas ao longo do tempo. Como as curvas de esvaziamento vesicular nos grupos controle e RCUI sem colectomia coincidiram ( $p=0,294$; Figura 4), o grupo não coincidente e com esvaziamento vesicular diminuído foi o grupo RCUI com colectomia (Figura 4). 


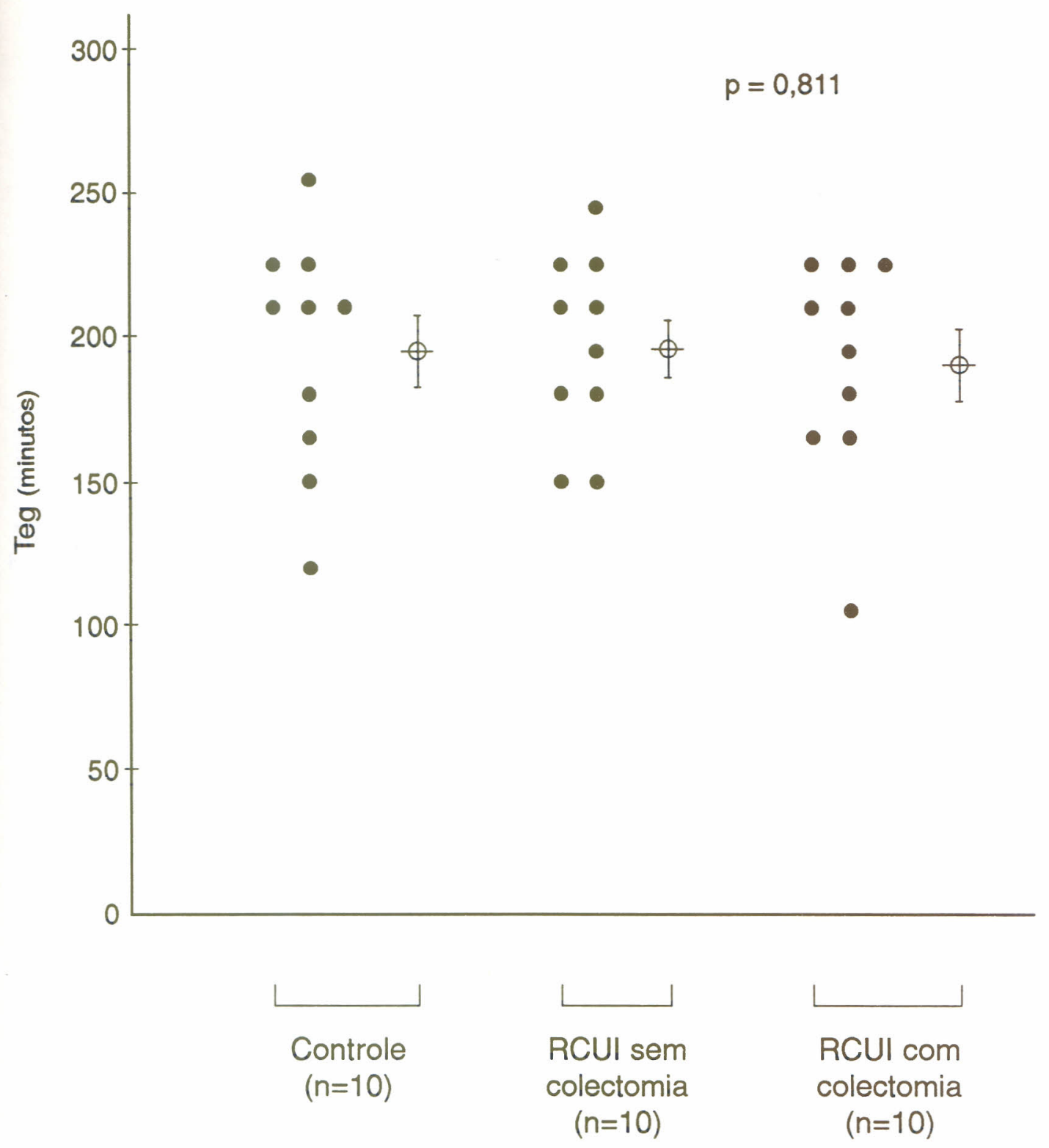

Figura 3 - Valores individuais e médios do tempo de esvaziamento gástrico (Teg) em minutos, nos grupos controle e retocolite ulcerativa inespecífica (RCUI) sem e com colectomia. Resultados expressos em média \pm erro padrão da média $(\phi)$. Teg: Controle, 195,0 \pm 12,8; RCUI sem colectomia, 196,5 \pm 9,9; RCUI com colectomia, $190,5 \pm 12,1$. 


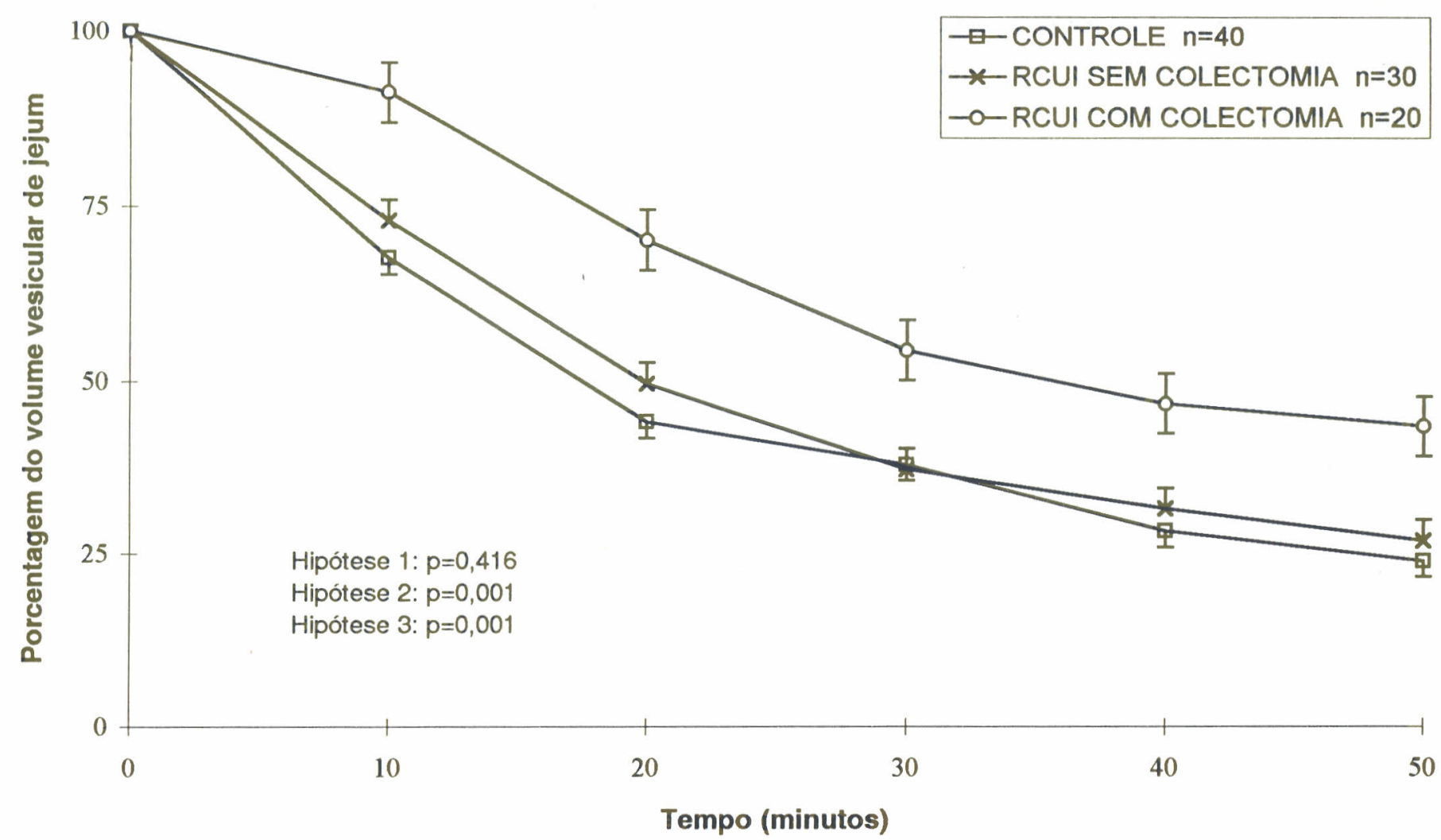

Figura 4 - Comparação entre as curvas de esvaziamento vesicular nos grupos controle, retocolite ulcerativa inespecífica (RCUI) sem e com colectomia. As medidas foram feitas em jejum (Tempo 0) e, após refeição de prova, a cada 10 minutos até 50 minutos. 0 volume vesicular foi calculado como porcentagem do volume vesicular de jejum. Valores expressos em média \pm EPM (erro padrão da média). Hipótese 1: paralelismo; Hipótese 2: coincidência; Hipótese 3: o volume vesicular é constante ao longo do tempo.

Obs.: Hipótese 1: o comportamento das curvas de esvaziamento vesicular foi semelhante (curvas paralelas) nos três grupos;

Hipótese 2: as curvas de esvaziamento vesicular nos grupos controle e RCUI sem colectomia coincidiram; a do grupo RCUl com colectomia não;

Hipótese 3: houve diminuição do volume vesicular ao longo do tempo nos três grupos. 
Tabela 7 - Porcentagens do volume vesicular de jejum em cada tempo do exame ultra-sonográfico nos grupos controle, retocolite ulcerativa inespecifica (RCUI) sem e com colectomia. As medidas foram feitas em jejum (Tempo $0=T_{0}=100 \%$ ) e, após refeição de prova, a cada 10 minutos até 50 minutos. Valores expressos em média \pm EPM (erro padrão da média).

\begin{tabular}{|c|c|c|c|c|c|c|}
\hline Grupos & $T_{0}$ & $T_{10}$ & $T_{20}$ & $T_{30}$ & $T_{40}$ & $T_{50}$ \\
\hline Controle $(n=40)$ & 100,0 & $67,6 \pm 2,8$ & $44,0 \pm 2,8$ & $37,8 \pm 2,5$ & $28,2 \pm 1,8$ & $23,9 \pm 1,5$ \\
\hline \multicolumn{7}{|l|}{ RCUI sem } \\
\hline colectomia $(n=30)$ & 100,0 & $72,9 \pm 3,6$ & $49,6 \pm 3,3$ & $37,2 \pm 3,1$ & $31,4 \pm 2,6$ & $26,8 \pm 2,3$ \\
\hline \multicolumn{7}{|l|}{ RCUI com } \\
\hline colectomia $(n=20)$ & 100,0 & $91,1 \pm 4,1$ & $70,1 \pm 4,8$ & $54,3 \pm 4,5$ & $46,7 \pm 4,2$ & $43,4 \pm 4,1$ \\
\hline
\end{tabular}

Hipótese 1 (parelelismo): $p=0,416$

Hipótese 2 (coincidência): $p=0,001$

Hipótese 3 (volume vesicular é constante ao longo do tempo): $p=0,001$

Obs.: Hipótese 1: o comportamento das curvas de esvaziamento vesicular foi semelhante (curvas paralelas) nos três grupos; Hipótese 2: as curvas de esvaziamento vesicular nos grupos controle e RCUI sem colectomia coincidiram; a do grupo RCUI com colectomia não; Hipótese 3: houve diminuição do volume vesicular ao longo do tempo nos três grupos. 
c) Hipótese 3: $p=0,001$, o que significa dizer que houve, nos três grupos, diminuição do volume vesicular ao longo do tempo e após estímulo alimentar (Figura 4). Esta diminuição ocorreu também nos intervalos 10 e 20, 20 e 30, 30 e 40, 40 e 50 minutos (em todos os casos $\mathrm{p}=0,001)$.

Na tabela 8 estão relacionados os valores médios referentes ao volume vesicular de jejum (VVJ), ao volume vesicular residual mínimo (VVRM), à diferença entre o VVJ e o VVRM ( $\triangle$ VVJ - VVRM), à porcentagem máxima de esvaziamento vesicular (PMEV) e ao tempo decorrido para a contração máxima vesicular (TCMV).

Não houve diferença estatisticamente significante, nos três grupos, entre os volumes vesiculares de jejum (VVJ) medidos em mililitros ( $p=0,063$; Tabela 8). Os volumes vesiculares residuais mínimos (VVRM) dos grupos controle e RCUI sem colectomia foram semelhantes. O mesmo ocorreu com os VVRM dos grupos RCUI sem e com colectomia. Contudo, o VVRM foi maior no grupo RCUI com colectomia quando comparado com o valor obtido para o grupo controle $(p=0,002$; Tabela 8$)$. A diferença entre o VVJ e o VVRM, que espelha a quantidade de bile que efetivamente foi eliminada da vesícula biliar $(119,158,213)$, foi maior no grupo RCUI sem colectomia que no com colectomia ( $\mathrm{p}=0,003$; Tabela 8).

A porcentagem máxima de esvaziamento vesicular (PMEV) foi menor no grupo RCUI com colectomia quando comparada com as dos grupos controle e RCUI sem colectomia ( $p=0,001$; Tabela 8$)$.

Os tempos decorridos para contração máxima da vesícula biliar (TCMV) foram semelhantes nos três grupos analisados ( $p=0,861$; Tabela 8). 
Tabela 8 - Volume vesicular de jejum (VVJ), volume vesicular residual mínimo (VVRM), diferença entre VVJ e VVRM ( $\triangle$ VVJ-VVRM), porcentagem máxima de esvaziamento vesicular (PMEV) e tempo para contração máxima vesicular (TCMV) nos grupos controle, retocolite ulcerativa inespecífica (RCUI) sem e com colectomia. Valores expressos em média \pm EPM (erro padrão da média).

\begin{tabular}{|c|c|c|c|c|c|}
\hline Grupos & $\begin{array}{l}\text { VVJ } \\
(\mathrm{ml})\end{array}$ & $\begin{array}{l}\text { VVRM } \\
\text { (ml) }\end{array}$ & $\begin{array}{c}\Delta \text { VVJ - VVRM } \\
(\mathrm{ml})\end{array}$ & $\begin{array}{c}\text { PMEV } \\
(\%)\end{array}$ & $\begin{array}{c}\text { TCMV } \\
\text { (minutos) }\end{array}$ \\
\hline Controle $(n=40)$ & $25,8 \pm 1,5$ & $5,9 \pm 0,6^{\#}$ & $19,9 \pm 1,1^{\#}$ & $77,8 \pm 1,4^{\#}$ & $44 \pm 1,5$ \\
\hline $\begin{array}{l}\text { RCUI sem } \\
\text { colectomia }(n=30)\end{array}$ & $33,9 \pm 3,5$ & $8,3 \pm 0,9^{\# \Delta}$ & $25,7 \pm 2,9^{4}$ & $74,5 \pm 2,2^{\#}$ & $45 \pm 1,1$ \\
\hline $\begin{array}{l}\text { RCUI com } \\
\text { colectomia }(n=20)\end{array}$ & $26,7 \pm 2,9$ & $10,3 \pm 1,1^{\wedge}$ & $16,3 \pm 2,2^{\#}$ & $59,8 \pm 3,8^{\wedge}$ & $44 \pm 1,8$ \\
\hline$p$ & 0,063 & 0,002 & 0,003 & 0,001 & 0,861 \\
\hline
\end{tabular}

Obs.: Os grupos com símbolos diferentes apresentaram diferença de médias estatisticamente significante $(p<0,05)$, em cada uma das variáveis. 


\subsubsection{Avaliação da reprodutibilidade do método ultra-sonográfico para estudo}

do esvaziamento vesicular

A reprodutibilidade do exame ultra-sonográfico foi satisfatória considerando as duas medidas do VVJ no mesmo indivíduo $(r=0,97 ; \mathrm{p}=0,524$; Figura 5).

\subsubsection{Influência do tempo de início dos sintomas, do diagnóstico, da cirurgia e da freqüência diária de evacuações pós-cirurgia sobre o esvaziamento vesicular}

Nos grupos RCUI sem e com colectomia não houve correlação entre a porcentagem máxima de esvaziamento vesicular (PMEV) e: a) tempo decorrido entre início dos sintomas e diagnóstico de RCUI e data do exame ultra-sonográfico; b) tempo decorrido entre o tratamento cirúrgico (colectomia) e data do exame ultrasonográfico; c) freqüência diária de evacuações pós-cirurgia e na época do exame ultra-sonográfico (Tabela 9). 


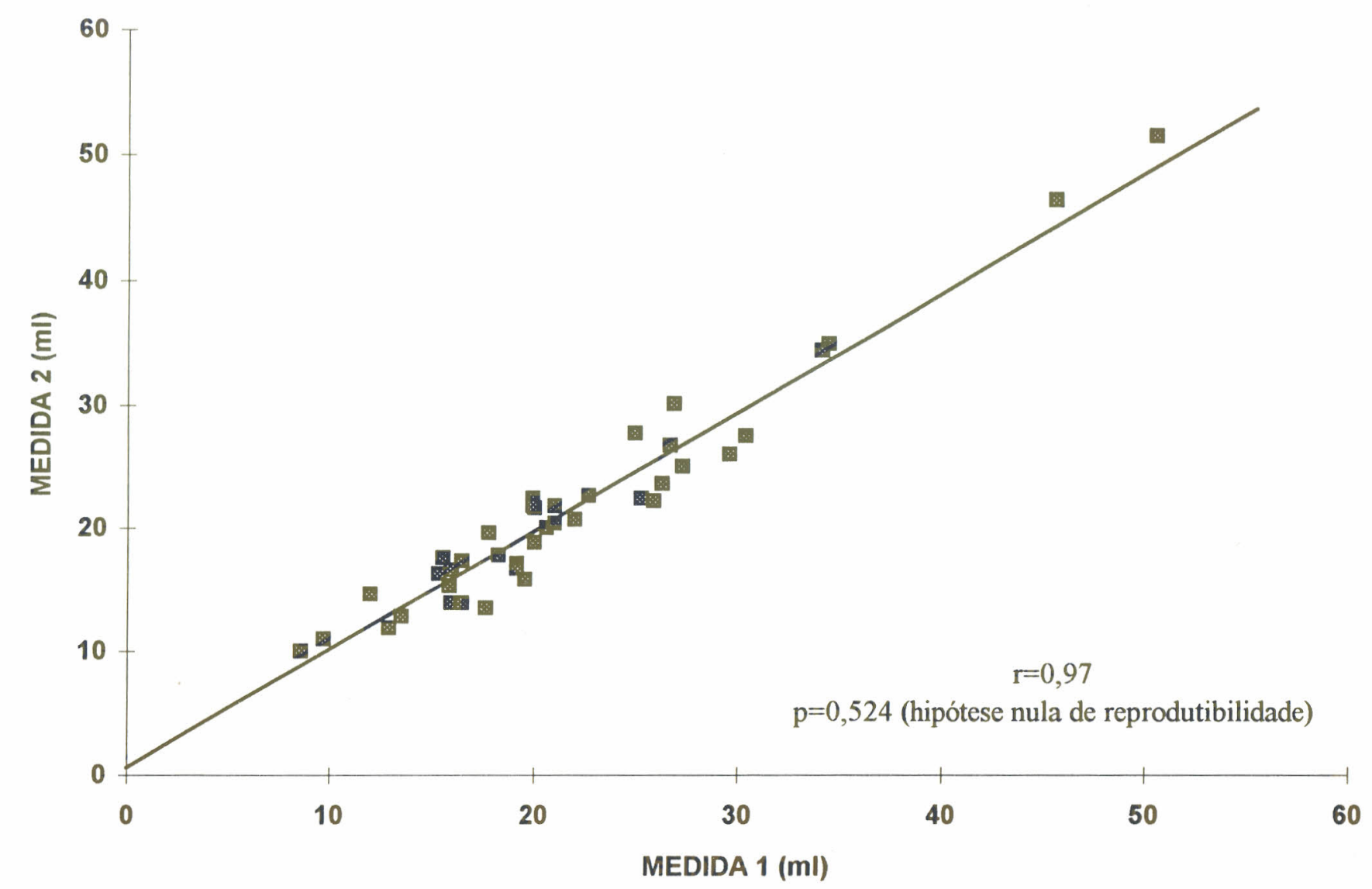

Figura 5 - Avaliação da reprodutibilidade do método ultra-sonográfico para cálculo do volume vesicular. Foram feitas duas medidas, em jejum e num mesmo indivíduo, do volume vesicular (ml). Total de 40 indivíduos. 
Tabela 9 - Correlação entre porcentagem máxima de esvaziamento vesicular (PMEV) e: a) tempo decorrido entre início dos sintomas (Ti) ou do diagnóstico (Td) de retocolite ulcerativa inespecífica (RCUI) e data do exame ultra-sonográfico (US); b) tempo decorrido entre o tratamento cirúrgico (colectomia) e data do exame US (Tc); c) freqüência diária de evacuações pós-cirurgia e na época do exame US.

\section{Grupos}

RCUI sem colectomia $(n=30)$

Ti $x$ PMEV

Td $\times$ PMEV

RCUI com colectomia $(n=20)$

Ti $x$ PMEV

0,09

Td $x$ PMEV

TC $\times$ PMEV

№ evacuações / dia x PMEV

0,03

$0,14 \bullet$

$-0,35$
0,13

$0,30^{\circ}$

0,496

0,110

p

0,716

0,901

0,556

0,199

- Coeficiente de correlação linear de Pearson

^ Coeficiente de correlação linear de Spearman 


\subsubsection{Influência da extensão da retocolite ulcerativa inespecífica (RCUI) sobre o esvaziamento vesicular}

Como pôde ser observado na Tabela 4, no grupo RCUI sem colectomia, o número de pacientes com RCUI do hemicólon esquerdo foi reduzido, prejudicando uma adequada análise estatística. Por conseguinte, optamos por reunir os pacientes com RCUI distal ( $n=10)$ e do hemicólon esquerdo $(n=5)$ num só grupo denominado RCUI hemicólon esquerdo. Os restantes $(n=15)$ apresentavam RCUI extensa.

Não houve diferença estatisticamente significante entre as porcentagens máximas de esvaziamento vesicular (PMEV) dos subgrupos RCUI hemicólon esquerdo $(n=15)$ e extensa $(n=15)($ PMEV RCUI hemicólon esquerdo $=72,1 \% \pm$ $3,4$; RCUI extensa $=76,9 \% \pm 2,9 ; \mathrm{p}=0,276)$.

\subsubsection{Influência da atividade inflamatória da retocolite ulcerativa inespecífica (RCUI) sobre o esvaziamento vesicular}

Na tabela 10 estão alistados os resultados, no grupo RCUI sem colectomia, sobre a influência dos vários parâmetros de atividade inflamatória (índice de atividade, hemoglobina, leucócitos, plaquetas, mucoproteínas e velocidade de hemossedimentação) sobre o esvaziamento vesicular. Não houve diferença 
Tabela 10 - Efeito dos vários parâmetros de atividade inflamatória no grupo retocolite ulcerativa inespecífica sem colectomia sobre a porcentagem máxima de esvaziamento vesicular (PMEV). Resultados espressos em média \pm EPM (erro padrão da média).

Parâmetros de atividade

n

PMEV

p

inflamatória

$(\%)$

1. Índice de atividade*

$\begin{array}{lrrr}>120 & 14 & 77,0 \pm 3,4 & 0,302 \\ \leq 120 & 16 & 72,3 \pm 2,9 & \end{array}$

2. Hemoglobina ( $g / d l)$

$$
\begin{aligned}
& \geq 12,0 \\
& <12,0
\end{aligned}
$$

$74,8 \pm 3,9$

$74,1 \pm 6,7$

0,882

3. Leucócitos $\left(\mathrm{n} \% / \mathrm{mm}^{3}\right)$

$\begin{array}{ccc}>10.000 & 8 & 72,4 \pm 3,3 \\ \leq 10.000 & 22 & 75,3 \pm 2,8\end{array}$

4. Plaquetas $\left(\mathrm{n} \% / \mathrm{mm}^{3}\right)$

$\begin{array}{lll}>400.000 & 10 & 71,4 \pm 4,3 \\ \leq 400.000 & 20 & 76,1 \pm 2,5\end{array}$

5. Mucoproteínas (mg/dl)

$\begin{array}{lll}>3,6 & 15 & 76,7 \pm 3,1 \\ \leq 3,6 & 15 & 72,3 \pm 3,1\end{array}$

6. VHS (mm, $1^{\text {a }}$ hora $)^{\star \star}$

$\begin{array}{lrr}>20 & 14 & 77,1 \pm 3,4 \\ \leq 20 & 16 & 72,3 \pm 2,9\end{array}$


estatisticamente significante entre as porcentagens máximas de esvaziamento vesicular (PMEV) dos vários subgrupos pesquisados.

\subsubsection{Influência do consumo de medicamentos sobre o esvaziamento vesicular}

Nos grupos RCUI sem e com colectomia, não houve diferença estatisticamente significante entre as porcentagens máximas de esvaziamento vesicular (PMEV) dos subgrupos sem e com consumo de medicamentos (Anexo B, Tabela 6).

3.3.6 Influência da presença de manifestações extra-intestinais sobre o esvaziamento vesicular

No grupo RCUI sem colectomia, as porcentagens máximas de esvaziamento vesicular (PMEV) dos subgrupos sem $(n=15)$ e com $(n=15)$ manifestações extra-intestinais foram semelhantes (PMEV subgrupo sem manifestações extra-intestinais $=76,4 \% \pm 3,0$; PMEV subgrupo com manifestações extra-intestinais $=72,6 \% \pm 3,3 ; \mathrm{p}=0,281$ ). 


\section{DISCUSSÃO}

A formação de cálculos de colesterol é o resultado da interação de três fatores etiopatogênicos $(85,86,91,93-6,214,215)$ : a) supersaturação biliar de colesterol; b) efeitos de agentes favorecedores ou inibidores da formação de cristais de colesterol (fatores pró e antinucleantes); c) estase vesicular. Assim, quando se avalia uma condição patológica relacionada com litíase biliar de colesterol, deve-se ter em mente que esses três fatores estão agindo, cada um em menor ou maior grau, levando à formação dos cálculos (93-96).

Pacientes com retocolite ulcerativa inespecífica (RCUI) não apresentam maior incidência de litíase biliar (216,217). Mas, nestes mesmos indivíduos, se o cólon for retirado a freqüência de colelitíase torna-se três vezes maior que a da população em geral $(184,185)$. Em 1991. Harvey et al (183) estudaram a bile de pacientes com RCUI sem e com colectomia. Nos pacientes colectomizados a bile revelou-se nitidamente litogênica, com supersaturação de colesterol. A concentração biliar de colesterol foi $28 \mathrm{mmol} / 1$ e o índice de saturação biliar de colesterol 1,32, bem maiores que os respectivos valores no grupo RCUI sem colectomia (14 mmol/l e 0,88). O tempo de nucleação (ou tempo decorrido para observação de cristais de 
colesterol) (183) foi bem menor no grupo colectomizado (média de 3 dias) do que nos pacientes sem colectomia (média de 15 dias). Estes resultados foram recentemente confirmados por Makino et al (218) que encontraram os seguintes valores para os pacientes colectomizados: concentração biliar de colesterol de 24 mmol/l, índice de saturação biliar de colesterol de 1,56 e tempo médio de nucleação de 6 dias (controles: $16 \mathrm{mmol} / 1 ; 1,04 ; 19$ dias). Neste mesmo trabalho (218), nos pacientes colectomizados e que desenvolveram litíase vesicular, a colecistectomia foi indicada e a análise da composição química dos cálculos revelou que o colesterol representava mais de $80 \%$ da constituição dos cálculos.

Embora a composição biliar já tenha sido estudada em pacientes colectomizados por RCUI $(183,218)$, a motilidade vesicular não havia sido avaliada até o presente trabalho. Escolhemos os métodos ultra-sonográficos para investigação do esvaziamento gástrico e vesicular (186-188) por serem métodos inócuos e amplamente validados na literatura médica $(7,19,85.215)$.

De acordo com nossos resultados, o esvaziamento vesicular foi diminuído nos pacientes do grupo RCUI com colectomia. Como salientado na Figura 4, já aos 10 minutos de exame, no grupo colectomizado, houve esvaziamento de apenas $10 \%$ do seu conteúdo de jejum, enquanto nos grupos controle e RCUI sem colectomia este valor foi de cerca de 30\%. Ao final do exame, a vesícula biliar continha ainda $45 \%$ do seu conteúdo de jejum no grupo RCUI com colectomia e em torno de $25 \%$ nos grupos controle e RCUI sem colectomia. Outrossim, no grupo RCUI com colectomia, os valores da porcentagem máxima de esvaziamento vesicular (PMEV) e da quantidade de bile eliminada da vesícula biliar durante o exame ( $\Delta$ VVJ-VVRM) foram menores do que os observados para o grupo RCUI sem colectomia (Tabela 8). 
As alterações do esvaziamento vesicular constatadas no grupo colectomizado não sofreram influência do tempo de esvaziamento gástrico (Figura 3), do tempo decorrido entre início dos sintomas, diagnóstico ou tratamento cirúrgico e data do exame ultra-sonográfico (Tabela 9), nem do consumo de medicamentos (Anexo B, Tabela 6). Como os ácidos biliares podem interferir na contração vesicular (ex., ácido cólico inibe a liberação duodenal de CCK) (219-224) e pacientes colectomizados perdem ácidos biliares nas fezes $(218,225-232)$, o número de evacuações diárias pós-cirurgia e na época do exame ultra-sonográfico foi levado em consideração no estudo do esvaziamento vesicular. Entretanto, não houve correlação entre freqüência diária de evacuações pós-cirurgia e esvaziamento vesicular (Tabela 9).

Nossos resultados no grupo colectomizado (Figura 4) estão relacionados com a colectomia em si e não com a doença de base (RCUI), pois pacientes com RCUI sem colectomia apresentaram esvaziamento vesicular semelhante ao do grupo controle independentemente do tempo decorrido entre o início dos sintomas ou do diagnóstico de RCUI e a data do exame ultra-sonográfico (Tabela 9), da atividade da doença (Tabela 10), do consumo de medicamentos (Anexo B, Tabela 6) e da presença de manifestações extra-intestinais (p. 40).

Como a colectomia poderia interferir na contração vesicular? Três mecanismos, que podem atuar conjuntamente, poderiam ocorrer:

a) em primeiro lugar, vários hormônios e peptídeos gastrintestinais são também produzidos em quantidades apreciáveis no cólon (26-28). Estas substâncias agem de modo harmonioso e equilibrado, estimulando e inibindo a contração vesicular sob estimulação alimentar e/ou neural (Tabela 1) (7,26-28). A retirada do cólon significa 
uma perda de grande área de produção de hormônios e peptídeos gastrintestinais e, conseqüentemente, um desequilíbrio na ação destes elementos sobre a contração vesicular. O resultado final poderia ser a diminuição da contração vesicular. Esta hipótese é reforçada pelo fato de doenças com reconhecida alteração na secreção gastrintestinal de peptídeos (ex., somatostatinoma, doença de Crohn) apresentarem hipomotilidade vesicular (161-166,168). A estase biliar permitiria maior tempo de contato entre a bile e a mucosa vesicular, com conseqüente aumento na reabsorção de água, superconcentração de colesterol, nucleação, retenção e coalescência dos cristais e, finalmente, formação de cálculos $(7,20,93,94)$;

b) em segundo lugar, sabe-se hoje que o mecanismo celular de contração da musculatura lisa vesicular requer a integridade da membrana da célula muscular e envolve duas vias: as vias fosfoinositídeo e adenosina monofosfato cíclica (AMFc) (17). Na via fosfoinositídeo, receptores para neurotransmissores, hormônios e peptídeos gastrintestinais, quando estimulados, desencadeiam uma seqüência de eventos ligada à ativação de enzimas na membrana celular do músculo liso vesicular, que culmina com a geração intracelular de inositol trifosfato (17,51). O inositol trifosfato promove, a partir do retículo endoplasmático, a liberação de cálcio, o qual ativa as quinases musculares que estimulam as proteínas contráteis actina e miosina. Desta forma, a estimulação da via fosfoinositídeo ocasiona contração vesicular; a inibição, o relaxamento (17). Na via AMFc, os receptores da membrana celular do músculo liso vesicular estimulam ou inibem a enzima adenilato ciclase, também presente na membrana celular (17). Quando estimulada, a adenilato ciclase produz aumento da AMFc intracelular que, através de uma proteinoquinase, inativa as quinases musculares com conseqüente relaxamento da musculatura vesicular. Ao contrário, se a adenilato ciclase for inibida o resultado final será a contração vesicular 
(17). É interessante ressaltar que a via fosfoinositídeo também ativa a fosfolipase A2, enzima intracelular que hidroliza o ácido araquidônico presente nos fosfolípides da membrana celular (17). O ácido araquidônico, por sua vez, gera prostaglandinas que inibem a adenilato ciclase $(7,17,20,233,234)$. Desta forma, as vias fosfoinositídeo e AMFc podem ser conectadas por intermédio das prostaglandinas. A contração causada pela CCK, por exemplo, é acompanhada de aumento do inositol trifosfato e do cálcio intracelulares e redução do $\operatorname{AMFc}(7,51)$. Isto prova que as duas vias (fosfoinositídeo e AMFc) são mobilizadas durante a contração da vesícula biliar sob estimulação da $\operatorname{CCK}(7,17,51)$. A colectomia, especialmente a acompanhada de bolsa ileal (ex., Kock, "J pouch") ou de ressecção extensa do îleo terminal (> 10cm), é seguida de perda fecal de ácidos biliares $(226-228,231,232)$. No caso da bolsa ileal, vários fatores podem explicar esta perda de ácidos biliares tais como: diminuição do tempo de trânsito intestinal (227), alterações na flora bacteriana $(218,227,231,232,235)$, atrofia de vilosidades e diminuição dos processos absortivos na bolsa ileal (236-238) ou redução da área absortiva $(226,228,232)$. Santavirta et al (239), estudando as possíveis causas de má absorção de ácidos biliares na bolsa ileal em pacientes com anastomose ileoanal, notaram que o que mais se correlacionou com a perda fecal de ácidos biliares foi a atrofia das vilosidades na mucosa da bolsa ileal. Seja qual for o mecanismo, o resultado final no colectomizado é a excreção fecal aumentada de ácidos biliares (218), diminuição do "pool" de ácidos biliares e supersaturação biliar de colesterol (183). O excesso de colesterol absorvido pela mucosa vesicular $(17,179)$ poderia alterar a relação colesterol: fosfolípides na membrana celular da célula epitelial e/ou do músculo liso, interferindo assim nos processos de sinalização entre membranas (17) e na mobilidade e função de receptores e enzimas $(17,51)$. De fato, colesterol em excesso na membrana celular de 
hemáceas e plaquetas pode interferir nas suas respectivas funções (17,51). Esta hipótese é corroborada pelo trabalho de Behar et al (51) em que a estimulação da contração, com CCK, de células musculares lisas vesiculares, obtidas de pacientes colectomizados por cálculos de colesterol, provocou pouca contração. Porém, a estimulação com inositol trifosfato gerou contração normal. Tais resultados indicam que em pacientes com cálculos de colesterol, os processos intracelulares de contração vesicular, desencadeados por ação do inositol trifosfato (ex., mobilização do cálcio, ativação das quinases musculares), estão íntegros. Contudo, a geração de inositol trifosfato está diminuída. O inositol trifosfato é formado a partir da ativação da fosfolipase $C$ presente na membrana da célula muscular lisa vesicular, ativação esta que pode ser prejudicada ou bloqueada pelo excesso de colesterol na membrana celular $(17,51,179)$;

c) em terceiro lugar, a hipocontratilidade vesicular observada nos pacientes colectomizados poderia ser explicada por alterações qualitativas dos ácidos biliares. Makino et al (218), analisando a composição dos ácidos biliares na bile vesicular de pacientes colectomizados em relação a um grupo controle, constataram que houve aumento de $50 \%$ na porcentagem de ácido cólico, enquanto o ácido deoxicólico tornou-se praticamente indetectável. Tal fato relaciona-se com a diminuição do processo de 7 - $\propto$ - desidroxilação, que normalmente ocorre no cólon sob ação bacteriana e que transforma o ácido cólico (primário) em deoxicólico (secundário) $(218,231,232)$. Também, este processo está sujeito às modificações da microflora bacteriana, do trânsito intestinal e dos mecanismos absortivos observados nos colectomizados $(218,231,232,235-239)$. Sabe-se que os ácidos biliares, em especial o ácido cólico, inibem a liberação duodenal de CCK (219-223), reduzem o número de receptores para CCK no músculo liso vesicular (223) e possivelmente aumentam a 
liberação intestinal de somatostatina (221). Estes efeitos, contudo, são diferentes a depender do ácido biliar considerado e não necessariamente ocorrem com todos os ácidos biliares $(219,240)$. Assim, o ácido cólico é um grande inibidor da contração vesicular e duas vezes mais potente, neste sentido, do que os ácidos quenodeoxicólico e deoxicólico (219). O ácido ursodeoxicólico, por outro lado, não interfere na liberação duodenal de CCK (240). Portanto, a presença em excesso do ácido cólico na bile dos pacientes colectomizados poderia reduzir a ação da CCK sobre a contração vesicular. Estas constatações reforçam o fato de que a colectomia compromete significativamente a formação dos ácidos biliares secundários $(218,231,232)$ e também, por causa da perda intestinal excessiva de ácidos biliares, ocasiona aumento da síntese hepática de ácidos biliares trihidroxilados como o ácido cólico (225). Na Figura 6 estão resumidos os três possíveis mecanismos acima descritos e envolvidos na formação de cálculos de colesterol em pacientes colectomizados.

Concluindo, o presente trabalho demonstra, pela primeira vez, que pacientes colectomizados por RCUI têm hipomotilidade vesicular, fato que contribui para a formação de cálculos $(7,20,85)$ e justifica a maior frequiência de colelitíase neste grupo de pacientes $(184,185)$. Além disso, como a estase vesicular precede a formação de cálculos (123-129, 131), agentes pró-cinéticos (20, 115, 119, 241-245) poderiam ser utilizados profilaticamente após a colectomia e em doses ajustáveis que não aumentassem a freqüência de evacuações. 


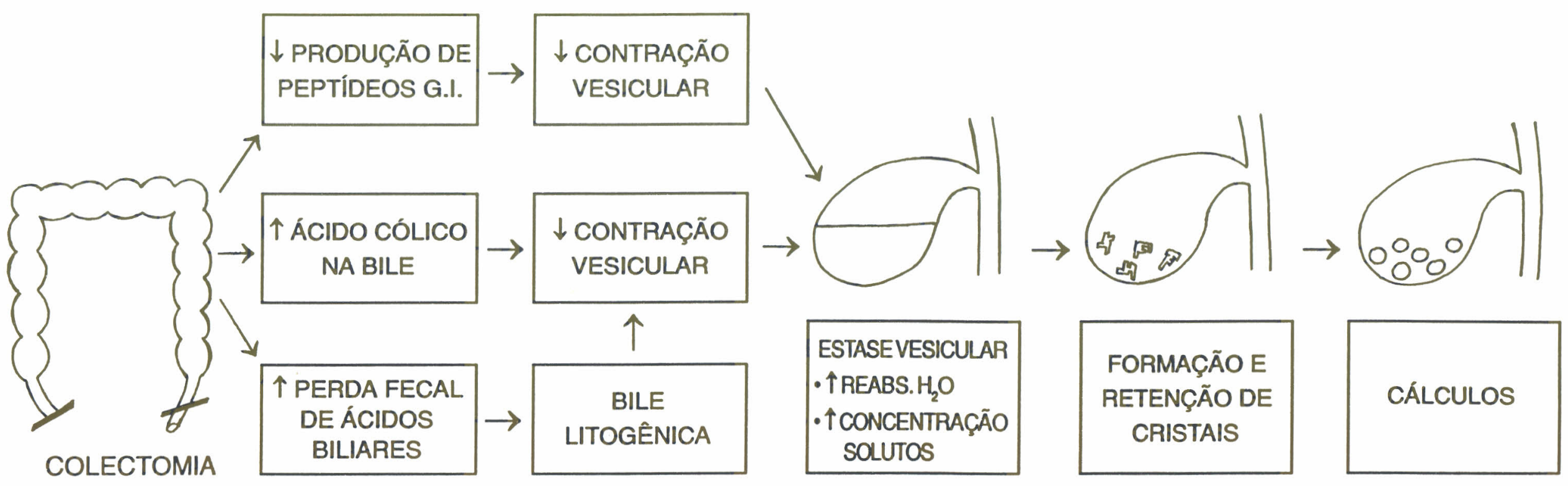

Figura 6 - Possíveis mecanismos envolvidos na formação de cálculos de colesterol em pacientes colectomizados. 


\section{CONCLUSÕES}

1. A porcentagem máxima de esvaziamento da vesícula biliar (PMEV), avaliada pela ultra-sonografia, foi menor $(59,8 \% \pm 3,8)$ no grupo retocolite ulcerativa inespecífica (RCUI) com colectomia em relação aos grupos controle $(77,8 \% \pm 1,4)$ e RCUI sem colectomia $(74,5 \% \pm 2,2)$.

2. A diminuição da PMEV no grupo RCUI com colectomia não sofreu influência do esvaziamento gástrico, do tempo decorrido entre início dos sintomas ou diagnóstico de RCUI e data do exame ultra-sonográfico (US), do tempo decorrido entre a colectomia e a data do exame US, da freqüência diária de evacuações póscirurgia na época do exame US e do consumo de medicamentos.

3. A diminuição da PMEV no grupo RCUI com colectomia relacionou-se com a colectomia em si, uma vez que a PMEV do grupo RCUI sem colectomia foi semelhante à do grupo controle independentemente do tempo decorrido entre início dos sintomas ou diagnóstico de RCUI e data do exame US, da extensão ou atividade inflamatória da doença, do consumo de medicamentos e da presença de manifestações extra-intestinais. 
6 ANEXOS 


\subsection{Anexo A}

Nome:

Idade: Sexo: Raça: Peso: Altura:

Profissão: Estado civil:

RG do HCFMUSP:

Endereço/Telefone:

\section{Esvaziamento vesicular}

Data do exame: Hora:

$\mathrm{V}(\mathrm{ml})=\pi / 6$ (Comprimento $(\mathrm{cm}) \times$ Largura $(\mathrm{cm}) \times$ Profundidade $(\mathrm{cm})$

$V=0,52(C \times L \times P)$

\begin{tabular}{|c|c|c|c|c|c|c|}
\hline Tempo & C & L & $\mathbf{P}$ & Volume & \multicolumn{2}{|c|}{$\%$} \\
\hline $\begin{array}{c}T_{0} \\
\text { (Jeium) }\end{array}$ & & & & $V_{0}=$ & \multicolumn{2}{|c|}{$(100)$} \\
\hline$T_{10}$ & & & & $V_{10}=$ & & ) \\
\hline$T_{20}$ & & & & $V_{20}=$ & & ) \\
\hline$T_{30}$ & & & & $V_{30}=$ & & ) \\
\hline$T_{40}$ & & & & $V_{40}=$ & ( & ) \\
\hline$T_{50}$ & & & & $V_{50}=$ & ( & ) \\
\hline
\end{tabular}

Volume vesicular de jejum $(\mathrm{VVJ})=$

Volume vesicular residual mínimo $($ VVRM $)=$

Diferença entre VVJ e VVRM ( $\triangle$ VVJ-VVRM $)=$

Porcentagem máxima de esvaziamento vesicular $(\mathrm{PMEV})=$ Observações: 
Nome:

Idade:

Sexo:

Raça:

Peso:

Altura:

Profissão:

Estado civil:

RG do HCFMUSP:

Endereço/Telefone:

$\begin{array}{ll}\text { Tempo de doença (meses): } & \text { Dos sintomas: } \\ & \text { Do diagnóstico: } \\ \text { Extensão da doença: } & \square \text { RCUl distal } \\ & \square \text { RCUl hemicólon esquerdo } \\ & \square \text { RCUl extensa }\end{array}$

Complicações e manifestações extra-intestinais:

Medicamentos:

\section{Índice de atividade (IA)}

\section{Pontuação}

1. Sangue nas fezes

Pouco ou nenhum 0

Presente 1

2. № evacuações/dia

$\begin{array}{ll}<4 & 1 \\ 5-7 & 2 \\ >8 & 3\end{array}$

3. VHS $\left(m m, 1^{a} h\right)$ :

4. Hemoglobina ( $\mathrm{g} / \mathrm{dl})$ :

5. Albumina $(\mathrm{g} / \mathrm{dl})$ :

IA = $60 \times$ sangue nas fezes $+0,5 \times$ VHS $+13 \times n^{\circ}$ evacuações/dia $-4 \times$ Hemoglobina $-15 \times$ Albumina +200

IA $($ RCUI $)=$

\section{Exames laboratoriais}

Mucoproteínas $(\mathrm{mg} / \mathrm{dl})$ :

Contagem de leucócitos $/ \mathrm{mm}^{3}$ :

Contagem de plaquetas $/ \mathrm{mm}^{3}$ :

Outros:

Observações:

Figura 2 - Modelo de ficha de identificação e de dados dos pacientes do grupo retocolite ulcerativa inespecífica (RCUI) sem colectomia. Para cada paciente foi anexada ficha de esvaziamento vesicular semelhante à descrita no Anexo A, Figura 1 (grupo controle). 
Nome:

Idade:

Sexo:

Raça:

Peso:

Altura:

Profissão:

Estado civil:

RG do HCFMUSP:

Endereço/Telefone:

Tempo de doença (meses): Dos sintomas:

Do diagnóstico:

Tipo de cirurgia: $\quad \square$ lleostomia tradicional

$\square$ lleostomia com bolsa ileal (Kock)

$\square$ íleo-reto anastomose

$\square$ Anastomose ileoanal com bolsa ileal

(Descrever tipo de Pouch)

Motivo da colectomia:

Tempo de cirurgia (meses):

Medicamentos:

Quadro clínico atual:

Observações:

Figura 3 - Modelo de ficha de identificação e de dados do grupo retocolite ulcerativa inespecífica (RCUI) com colectomia. Para cada paciente foi anexada ficha de esvaziamento vesicular semelhante à descrita no Anexo A, Figura 1 (grupo controle). 
Nome:

Idade: Sexo: Raça: Peso: Altura:

Profissão: Estado civil:

RG do HCFMUSP:

Endereço/Telefone:

Grupo:

\section{Esvaziamento gástrico}

Data do exame:

Hora:

Área antral $\left(\mathrm{cm}^{2}\right)=$ Dlâmetro longltudinal $(A) \times$ Dlâmetro anteroposterior $(B) \times 0,7854$

\begin{tabular}{|c|c|c|c|c|}
\hline Tempo (T) & Hora & A & B & Área antral \\
\hline$T(-1)$ (Jjejum) & & & & \\
\hline$T(0)$ (Logo apos refeiçä) & & & & \\
\hline$T(15)$ & & & & \\
\hline$T(30)$ & & & & \\
\hline$T(45)$ & & & & \\
\hline$T(60)$ & & & & \\
\hline$T(75)$ & & & & \\
\hline$T(90)$ & & & & \\
\hline$T(105)$ & & & & \\
\hline$T(120)$ & & & & \\
\hline$T(135)$ & & & & \\
\hline$T(150)$ & & & & \\
\hline$T(165)$ & & & & \\
\hline$T(180)$ & & & & \\
\hline$T(195)$ & & & & \\
\hline$T(210)$ & & & & \\
\hline$T(225)$ & & & & \\
\hline$T(240)$ & & & & \\
\hline$T(255)$ & & & & \\
\hline$T(270)$ & & & & \\
\hline$T(285)$ & & & & \\
\hline$T(300)$ & & & & \\
\hline
\end{tabular}

Observações:

Figura 4 - Modelo de ficha de avaliação do esvaziamento gástrico por método ultra-sonográfico. 
Tabela 1 - Características dos grupos retocolite ulcerativa inespecífica (RCUI) sem e com colectomia: tempo decorrido entre início dos sintomas (Ti) ou diagnóstico $(\mathrm{Td})$ e data do exame ultra-sonográfico.

Grupos

n

$\mathrm{Ti}$ (meses; média $\pm \mathrm{EPM}^{\star}$ )

Td (meses; média \pm EPM)

RCUI sem

colectomia

30

$94,0 \pm 13,9$

$58,6 \pm 9,2$

RCUI com

colectomia

20

$127,3 \pm 20,4$

$104,0 \pm 14,5$ 
Tabela 2 - Relação dos medicamentos que vinham sendo ingeridos pelos pacientes dos grupos retocolite ulcerativa inespecífica (RCUI) sem e com colectomia na época do exame ultra-sonográfico (SSZ = sulfasalazina; Ac. fól. = Ácido fólico; Pred. = Prednisona; Aza. = Azatioprina; 5-ASA = Ácido 5aminosalicílico).

Grupo RCUI sem

colectomia $(n=30)$
Grupo RCUI com

colectomia $(n=20)$

$S S Z+$ Ac. fól.

$8^{*}$

SSZ + Pred. + Ac. fól.

6

Pred. + Aza.

2

Pred.

1

Metronidazol

5-ASA supositórios

SSZ

Elixir paregórico

Loperamida

Hioscina

Digoxina

Total 
Tabela 3 - Características do grupo retocolite ulcerativa inespecífica (RCUI) com colectomia : tipo de cirurgia, tempo decorrido entre o tratamento cirúrgico e a data do exame ultra-sonográfico (Tc) e freqüência diária de evacuações na época do exame ultra-sonográfico.

\begin{tabular}{|c|c|c|c|c|c|c|}
\hline \multirow[t]{2}{*}{ Grupo } & \multicolumn{4}{|c|}{ Tipo de cirurgia } & \multirow{2}{*}{$\begin{array}{c}\text { Tc } \\
(\text { meses; } \\
\left.\text { média } \pm \mathrm{EPM}^{\star 1}\right)\end{array}$} & \multirow{2}{*}{$\begin{array}{c}\text { № de evacuações/dia *2 } \\
\text { (média } \pm \text { EPM })\end{array}$} \\
\hline & $\begin{array}{l}\text { Pouch } \\
\text { (n) }\end{array}$ & $\begin{array}{c}\text { Pouch + ileostomia } \\
\text { em alça }(n)\end{array}$ & $\begin{array}{l}\text { Ileostomia } \\
(n)\end{array}$ & $\begin{array}{c}\text { ileo-reto } \\
\text { anastomose(n) }\end{array}$ & & \\
\hline
\end{tabular}

\section{RCUI com}

colectomia

14

3

2

1

$29,8 \pm 5,6$

$5,8 \pm 0,7$

$(n=20)$

*1 $E P M=$ erro padrão da média

*2 Só considerado nos pacientes sem ileostomia $(n=15)$ 
Tabela 4 - Relação das manifestações extra-intestinais observadas nos pacientes do grupo retocolite ulcerativa inespecífica (RCUI) sem colectomia.

Aftas orais + artralgia

Aftas orais + sacroileíte

Pioderma gangrenoso

Total 
Tabela 5 - Índice de atividade inflamatória (IA) para a retocolite ulcerativa inespecífica (RCUI) de acordo com Seo et al, 1992 (referência 206).

\section{Pontuação}

1. Sangue nas fezes

Pouco ou nenhum 0

Presente 1

2. Número de evacuações/dia

$\begin{array}{ll}<4 & 1 \\ 5-7 & 2 \\ >8 & 3\end{array}$

3. Velocidade de hemossedimentação - $\mathrm{mm}, 1^{\mathrm{a}} \mathrm{h}$ (VHS)

4. Hemoglobina - $g / d l$

$(\mathrm{Hb})$

5. Albumina - g/dl

(Alb)

IA $($ RCUI $)=60 \times$ sangue nas fezes $+0,5 \times$ VHS $+13 \times n^{\circ}$ evacuações/dia -4 x Hb -15 x Alb +200 
Tabela 6 - Efeito do consumo de medicamentos sobre o esvaziamento vesicular (PMEV = porcentagem máxima de esvaziamento vesicular) nos grupos retocolite ulcerativa inespecífica (RCUI) sem e com colectomia. Resultados expressos em média \pm EPM (erro padrão da média). A relação dos medicamentos usados encontra-se no Anexo B, Tabela 2.

\section{Grupos e subgrupos}

RCUI sem colectomia

Sem medicamento

Com medicamento

RCUI com colectomia
11

19

14

6
PMEV (\%)

p

$$
76,1 \pm 3,9
$$

\section{0,612}

$$
73,7 \pm 2,8
$$

$57,7 \pm 4,2$

$$
0,430
$$




\section{REFERÊNCIAS BIBLIOGRÁFICAS}

1. SANFORD, P.A. Liver and secretions of pancreas and duodenum. In: Hardy, R.N.; Hobsley, M.; Saunders, K.B., ed. Digestive System Physiology. London, Edward Arnold Ltd., 1982. p.54-74. (Physiological Principles in Medicine, v.3)

2. WEISBRODT, N.W. Bile production, secretion and storage. In: Johnson, L.R., ed. Gastrointestinal Physiology. 2. ed. St Louis, C.V. Mosby Company, 1981. p.84-94.

3. HOFMANN, A.F. Biliary secretion and excretion. In: West, J.B., ed. Best and Taylor's Physiological Basis of Medical Practice. 12. ed. Baltimore, Williams \& Wilkins, 1991. p. 675-92.

4. HOFMANN, A.F. The enterohepatic circulation of bile acids in health and disease. In: Sleisenger, M.H.; Fordtran, J.C., ed. Gastrointestinal Disease: pathophysiology, diagnosis, management. 5. ed. Philadelphia, W.B. Saunders Company, 1993. v.1, p. 127-50. 
5. BOLT, R.J.; PALMER, P.E.S.; RUEBNER, B.H.; WATSON, D.W. The

Digestive System. New York, John Wiley \& Sons, 1983. Cap.6, p.189-265:

The liver.

6. HOFMANN, A.F. Bile, bile acids and gallstones: will new knowledge bring new power? A.J.R., v.151, p.5-12, 1988.

7. TIERNEY, S.; PITT, H.A.; LILLEMOE, K.D. Physiology and pathophysiology of gallbladder motility. Surg.Clin.North Am., v.73, p.1267-90, 1993.

8. SCHARSCHMIDT, B.F. Bile formation and cholestasis. In: Zakim, D.; Boyer, T.D., ed. Hepatology: a textbook of liver disease. 2. ed. Philadelphia, W.B. Saunders Company, 1990. v.1, p. 303-40.

9. FRIERSON, H.F. The gross anatomy and histology of the gallbladder, extrahepatic bile ducts, vateriam system and minor papilla. Am.J.Surg.Pathol., v.13, p.146-62, 1989.

10. DAVENPORT, H.W. Physiology of the digestive tract. Chicago, Year Book Medical Publishers, INC., 1982. Cap. 11, p.155-78: Secretion of the bile.

11. DAVISON, J.S. Physiology of extrahepatic bile transport. In: Bouchier, I.A..D.; Allan, R.N.; Hodgson, H.J.F.; Keighley, M.R.B., ed. Gastroenterology: clinical science and practice. 2. ed. London, W.B. Saunders Company, 1993. v.2, p. 1688-92. 
12. SVANVIK, J. Role of gallbladder in modifying hepatic bile composition. In: Tavaloni, N.; Berk, P.D., ed. Hepatic transport and bile secretion: physiology and pathophysiology. New York, Raven Press, Ltd., 1993. p. 607-18.

13. ROSE, R.C. Absorptive functions of the gallbladder. In: Johnson, L.R., ed. Physiology of the gastrointestinal tract. 2. ed. New York, Raven Press, Ltd., 1987. v.2, p. 1455-68.

14. BOLT, R.J.; PALMER, P.E.S.; RUEBNER, B.H.; WATSON, D.W. The digestive system. New York, John Wiley \& Sons, 1983. Cap. 7., p.267-81: The gallbladder.

15. PAPAGEORGIOU, G.; LYNN, J.A. The physiology of the extrahepatic biliary tree. In: Wright, R.; Millward-Sadler, G.H.; Alberti, K.G.M.M.; Karran, S. ed. Liver and biliary disease: pathophysiology, diagnosis, management. 2. ed. London, Baillière Tindall, W.B. Saunders Company, 1985. p. 267-76.

16. BEHAR, J. Physiology of the biliary tract. In: Haubrich, W.S.; Schaffner, F.; ed. Bockus Gastroenterology. 5. ed. Philadelphia. W.B. Saunders Company, 1995. v.3, p.2554-72.

17. LaMORTE, W.W. Biliary motility and abnormalities associated with cholesterol cholelithiasis. Curr.Opin.Gastroenterol., v.9, p.810-6, 1993.

18. CATAlano, M.F.; HOGAN, W.J. Biliary motility. Curr. Opin. Gastroenterol., v.10, p.558-66, 1994. 
19. RYAN, J.P. Motility of the gallbladder and biliary tree. In: Johnson, L.R., ed. Physiology of the gastrointestinal tract. 2. ed. New York, Raven Press, Ltd., 1987. v.1, p.695-721.

20. O'DONNELL, L.J.D.; FAIRCLOUGH, P.D. Gallstones and gallbladder motility. Gut, v.34, p.440-3, 1993.

21. FISHER, R.S.; ROCK, E.; MALMUD, L.S. Gallbladder emptying response to sham feeding in humans. Gastroenterology, v.90, p.1854-7, 1986.

22. HANSEN, W.E.; MAURER, H.; HABERLAND, H. The effect of sham-feeding on gallbladder volume and circulation of bile acids. Hepato-gastroenterol., v.29, p.108-10, 1982.

23. HOPMAN, W.P.M.; JANSEN, J.B.M.J.; ROSENBUSCH, G.; LAMERS, C.B.H.W. Cephalic stimulation of gallbladder contraction in human: role of cholecystokinin and the cholinergic system. Digestion, v. 38, p.197-203, 1987.

24. ELLENBOGEN, S.; JENKINS, S.A.; GRIME, J.S.; CRITCHLEY, M.; MACKIE, C.R.; BAXTER, J.N. Preduodenal mechanisms in initiating gallbladder emptying in man. Br. J. Surg., v.75, p.940-5, 1988.

25. YAMAMURA, T.; TAKAHASHI, T.; KUSONOKI, M.; KANTOH, M.; SEINO, Y.; UTSUNOMIYA, J. Gallbladder dynamics and plasma cholecystokinin responses after meals, oral water, or sham feeding in healthy subjects. Am.J.Med. Sci., v.295, p. 102-7, 1988. 
26. GREEN, D.W.; GOMEZ, G. Greeley, G.H. Jr. Gastrointestinal peptides. Gastroenterol. Clin. North Am., v.18, p.695-733, 1989.

27. DOCKRAY, G.J. Physiology of enteric neuropeptides. In: Johnson, L.R., ed. Physiology of the gastrointestinal tract. 2. ed. New York, Raven Press, Ltd., 1984. v.1, p.41-66.

28. WALSH, J.H. Gastrointestinal hormones. In: Johnson, L.R., ed. Physiology of the gastrointestinal tract. 2. ed. New York, Raven Press, Ltd., 1987. v.1, p.181-253.

29. LENZ, H.J.; ZIMMERMAN, F.G.; MESSMER, B. Regulation of canine gallbladder motility by brain peptides. Gastroenterology, v.104, p.1678-85, 1993.

30. DEBAS, H.T.; YAMAGISHI, T. Evidence for a pyloro-cholecystic reflex for gallbladder contraction. Ann. Surg., v.190, p.170-5, 1979.

31. FRIED, G.M.; OGDEN, W.D.; GREELEY, G.; THOMPSON, J.C. Correlation of release and actions of cholecystokinin in dogs before and after vagotomy. Surgery, v.93, p.786-91, 1983.

32. PADBURY, R.T.A.; FURNESS, J.B.; BAKER, R.A.; TOOULI, J.; MESSENGER, J.P. Projections of nerve cells from the duodenum to the sphincter of Oddi and gallbladder of the Australian possum. Gastroenterology, v.104, p.130-6, 1993. 
33. GO, V.L.W.; HOFMANN, A.F.; SUMMERSKILL, W.H.J. Pancreozymin bioassay in man based on pancreatic enzyme secretion: potency of specific aminoacids and other digestive products. J.Clin.Invest., v.49, p.1558-64, 1970.

34. KONTUREK, S.; TASLER, J.; OBTULOWICZ, W. Localization of cholecystokinin release in intestine of the dog. Am.J.Physiol., v.222, p.1620, 1972.

35. MEYER, J.; JONES, R. Canine pancreatic responses to intestinally perfused fat and products of fat digestion. Am.J.Physiol., v. 226, p. 1178-87, 1974.

36. MEYER, J.; KELLY, G.; SPINGOLA, L.; JONES, R. Canine gut receptors mediating pancreatic responses to luminal L - aminoacids. Am.J.Physiol., v. 231, p. 669-77, 1976.

37. MALAGELADA, J.R.; DiMAGNO, E.P.; SUMMERSKILL, W.H.J.; GO, V.L.W. Regulation of pancreatic and gallbladder functions by intraluminal fatty acids and bile acids in man. J.Clin.Invest., v.58, p.493-9, 1976.

38. SOLOMON, T.E. Control of exocrine pancreatic secretion. In: Johnson, L.R., ed. Physiology of the gastrointestinal tract. 2. ed. New York, Raven Press, Ltd., 1987. v.2, p.1173-1207.

39. SOLCIA, E.; CAPELLA, C.; FIOCHA, R.; CORNAGGIA, M.; BOSI, F. The gastroenteropancreatic endocrine system and related tumors. Gastroenterol. Clin. North Am., v.18, p.671-93, 1989. 
40. SOLCIA, E.; CAPELLA, C.; BUFFA, R.; USELLINI, L.; FIOCCA, R.; SESSA,

F. Endocrine cells of the digestive system. In: Johnson, L.R., ed. Physiology of the gastrointestinal tract. 2. ed. New York, Raven Press, Ltd., 1987. v.2, p.111-30.

41. DAMIÃO, A.O.M.C.; SIPAHI, A.M.; MORAES-FILHO, J.P.P. Noções de anatomia e fisiologia do intestino delgado. In: Moraes-Filho, J.P.P., ed. Manual de Gastroenterologia. 2. ed. São Paulo, Livraria Roca, Ltda., 1993. p.161-73.

42. WIENER, I.; INOUE, K.; FAGAN, C.J.; LILJA, P.; WATSON, L.C.; THOMPSON, J.C. Release of CCK in man: correlation of blood levels with gallbladder contraction. Ann. Surg., v.194, p.321-7, 1981.

43. BEHAR, J.; BIANCANI, P. Effect of cholecystokinin and the octapeptide of cholecystokinin on the feline sphincter of Oddi and gallbladder. J. Clin. Invest., v.66, p.1231-9, 1980.

44. LIN, T.M. Actions of gastrointestinal hormones and related peptides on the motor functions of the biliary tract. Gastroenterology, v.69, p.1006-22, 1975 .

45. STUBBS, R.S.; STABILE, B.E. Role of cholecystokinin in pancreatic exocrine response to intraluminal aminoacids and fat. Am.J.Physiol.,v.248, p. G34752,1985 . 
46. SCHJOLDAGER, B.; MOLERO, X.; MILLER, L.J. Functional and biochemical characterization of the human gallbladder muscularis cholecystokinin receptor. Gastroenterology, v.96, p.1119-25, 1989.

47. STEIGERWALT, R.W.; GOLDFINE, I.D.; WILLIAMS, J.A. Characterization of cholecystokinin receptors on bovine gallbladder membranes. Am.J.Physiol., v.247, p. G709-14, 1984.

48. SCHIMIDT, W.E.; CREUTZFELDT, W.; SCHLESER, A.; CHOUDHURY, A.R.; NUSTEDE, R.; HÖCKER, M.; NITSCHE, R.; SOSTMANN, H.; ROVATI, L.C.; FÖLSCH, U.R. Role of CCK in regulation of pancreaticobiliary functions and GI motility in humans: effects of loxiglumide. Am.J.Physiol., v.260, p. G197-206, 1991.

49. TOKUNAGA, Y.; COX, K.L.; COLEMAN, R.; CONCEPCION, W.; NAKAZATO, P.; ESQUIVEL, C.O. Characterization of cholecystokinin receptors on the human gallbladder. Surgery, v.113, p.155-62, 1993.

50. PORTINCASES, P.; HOWARD, A.; MURPHY, G.M.; DOWLING, R.H. Cholecystokinin receptor binding to human gallbladder myocyte membranes. Gut., v.27, p. A1261, 1986. [Resumo]

51. BEHAR, J.; RHIM, B.Y.; THOMPSON, W.; BIANCANI, P. Inositol triphosphate restores impaired human gallbladder motility associated with cholesterol stones. Gastroenterology,v.104, p.563-8,, 1993. 
52. JEBBINK, M.C.W.; MASCLEE, A.A.M.; VAN DER KLEIJ, F.G.H.; SCHIPPER, J.; ROVATI, L.C.; JANSEN, J.B.M.J.; LAMERS, C.B.H.W. Effect of loxiglumide and atropine on erythromycin - induced reduction in gallbladder volume in human subjects. Hepatology, v.16, p.937-42, 1992.

53. BEGLINGER, C.; HILDEBRAND, P.; ADLER, G.; WERTH, B.; LUO, H.; DELCO, F.; GYR, K. Postprandial control of gallbladder contraction and exocrine pancreatic secretion in man. Eur. J. Clin. Invest., v.22, p.827-34, 1992.

54. FISHER, R.S.; ROCK, E.; MALMUD, L.S. Cholinergic effects on gallbladder emptying in humans. Gastroenterology, v.89, p.716-22, 1985.

55. HANYU, N.; DODDS, W.J.; LAYMAN, R.D.; HOGAN, W.J.; CHEY, W.Y.; TAKAHASHI, I. Mechanisms of cholecystokinin-induced contraction of the Opossum gallbladder. Gastroenterology, v. 98, 1299-1306, 1990.

56. HOPMAN，W.P.M.; JANSEN，J.B.M.J. ; ROSENBUSCH，G.; LAMERS, C.B.H.W. Role of cholescystokinin and the cholinergic system in intestinal stimulation of gallbladder contraction in man. Hepatology, v.11, p.261-5, 1990.

57. BROTSCHI, E.A.; PATTAVINO; J.; WILLIAMS, L.F. Jr. Intrinsec nerves affect gallbladder contraction in the Guinea pig. Gastroenterology, v.99, p.826-30, 1990. 
58. TAKAHASHI, T.; MAY, D.; OWYANG, C. Cholinergic dependence of gallbladder response to cholecystokinin in the Guinea pig in vivo. Am. J. Physiol., v.261, p. G565-9, 1991.

59. MARZIO, L.; Di GIAMMARCO, A.M.; NERI, M.; CUCCUROLlO, F.; MALFERTHEINER, P. Atropine antagonizes cholecystokinin and cerulein induced gallbladder evacuation in man: a real time ultrasonography study. Am. J. Gastroenterol., v.80, p.1-4, 1985.

60. STRAH, K.M.; PAPPAS, T.N.; MELENDEZ, R.L.; DEBAS, H.T. Anticholinergic influence on exogenous and endogenous stimulation of gallbladder contraction. Gastroenterology, v.88, p. 1601, 1985. [Resumo]

61. GREENEN, J.E.; HOGAN, W.J.; DODDS, W.J.; STEWARD, E.T. ARNDORFER, R.C. Intraluminal pressure recording from the human sphincter of Oddi. Gastroenterology, v.78, p.317-24, 1980.

62. SCOTT, R.B.; STRASBERG, S.M.; El-SHARKAWY, T.Y.; DIAMANT, N.E. Fasting canine biliary secretion and the sphincter of Oddi. Gastroenterology, v.87, p.793-804, 1984

63. TOOULI, J.; HOGAN, W.J.; GREENEN, J.E.; DODDS, W.J.; ARNDORFER, R.C. Action of cholecystokinin - octapeptide on sphincter of Oddi basal pressure and phasic wave activity in humans. Surgery, v.92, p.497-503, 1982. 
64. MOURELlE, M.; GUARNER, F.; MOLERO, X.; MONCADA, S.; MALAGELADA, J. Regulation of gallbladder motility by the arginine nitric oxide pathway in Guinea pigs. Gut, v.34, p.911-5, 1993.

65. KONTUREK, S.K.; KONTUREK, P.C. Role of nitric oxide in the digestive system. Digestion, v.56, p.1-13, 1995.

66. ITOH, Z.; TAKAHASHI, I. Periodic contractions of the canine gallbladder during the interdigestive state. Am. J. Physiol., v.240, p.G183-9, 1981.

67. ITOH, Z.; TAKAHASHI, I.; NAKAYA, M.; SUZUKI, T.; ARAI, H.; WAKABAYASHI, K. Interdigestive gallbladder bile concentration in relation to periodic contraction of gallbladder in the dog. Gastroenterology, v.83, p.645-51, 1982.

68. KRAGLUND, K.; HJERMIND, J.; JENSEN, F.T.; STODKILDE-JORGENSEN, H.; OSTER-JORGENSEN, E.; PEDERSEN, S.A. Gallbladder emptying and gastrointestinal cyclic motor activity in humans. Scand J. Gastroenterol., v.19, p.990-4, 1984

69. TRAYNOR, O.J.; DOZOIS, R.R.; Di MAGNO, E.P. Canine interdigestive and prostprandial gallbladder motility and emptying. Am. J. Physiol., v.246, p.G426-32, 1984

70. MARZIO, L.; NERI, M.; CAPONE, F.; FELICE, F.; ANGELIS, C.; MEZZETTI, A.; CUCCURULLO, F. Gallbladder contraction and its relation to interdigestive duodenal motor activity in normal human subjects. Dig. Dis. Sci., v.33, p.540-4, 1988. 
71. QVIST, N.; OSTER-JORGENSEN, E.; RASMUSSEN, L.; KRAGLUND, K.; PEDERSEN, S.A. The relationship between gallbladder dynamics and the migrating motor complex in fasting healthy subjects. Scand. J. Gastroenterol., v.23, p. 562-6, 1988.

72. NILSSON, B.I.; SVENBERG, T.; TOLLSTRÖM, T.; HELLSTRÖM, P.M.; SAMUELSON, K.; SCHNELL, P. Relationship between interdigestive gallbladder emptying, plasma motilin and migrating motor complex in man. Acta Physiol. Scand., v.139, p.55-61, 1990.

73. STOLK, M.F.J.; VAN EPERCUM, K.J.; SMOUT, A.J.P.M.; AKKERMANS, L.M.A.; JANSEN， J.B.M.J.; LAMERS， C.B.H.W.; PEETERS， T.L.; VANBERGE- HENEGOUWEN, G.P. Motor cycles with phase III in antrum are associated with high motilin levels and prolonged gallbladder emptying. Am. J. Physiol., v.264, p.G596-600, 1993.

74. QVIST, N.; OSTER-JORGENSEN, E.; PEDERSEN, S.A.; RASMUSSEN, L.; HOVENDAL, C.; HOLST, J.J. Increases in plasma motilin follow each episode of gallbladder emptying during the interdigestive period, and changes in serum bile acid concentration correlate to plasma motilin. Scand. J. Gastroenterol., v.30, p.122-7, 1995.

75. DOWLING, R.H. Gallstone formation in man. Ital. J. Gastroenterol., v.10, p.12-8, 1978. Supplement 1.

76. LaRUSSO, N.F. Pathogenesis of gallstones, including predisposing factors. Pract. Gastroenterol., v.5, p.21-31, 1981. 
77. ERLINGER, S. Comment se forme un calcul de cholestérol? Gastroenterol. Clin. Biol., v.18, p.984-7, 1994.

78. CAREY, M.C.; CAHALANE, M.J. Whiter biliary sludge? Gastroenterology, v.95, p.508-23, 1988.

79. GROEN, A.V.; DRAPERS, J.A.G.; TYTGAT, G.N.J. Cholesterol nucleation and gallstone formation. J.Hepatol., v.6, p. 383-7, 1988.

80. SCHOENFIELD, L.J.; CAREY, M.C.; MARKS, J.W.; THISTLE, J.L. Gallstones: un update. Am. J. Gastroenterol., v.84, p.999-1007, 1989.

81. BUSCH, N.; MATERN, S. Current concepts in cholesterol gallstone pathogenesis. Eur. J. Clin. Invest., v.21, p.453-60, 1991.

82. OFFNER, G.D.; NUNES, D.P. Pathogenesis of cholesterol gallstones. Curr. Opin. Gastroenterol., v.10, p.546-51, 1994.

83. JUVONEN, T. Pathogenesis of gallstones. Scan. J. Gastroenterol., v.29, p.577- 82, 1994.

84. HAY, D.W.; CAREY, M.C. Pathophysiology and pathogenesis of cholesterol gallstone formation. Sem. Liver Dis., v. 10, p.159-70, 1990.

85. EVERSON, G.T. Gallbladder function in gallstone disease. Gastrenterol. Clin. North Am., v.20, p. 85-110, 1991.

86. CAREY, M.C. Pathogenesis of gallstones. Am. J. Surg., v.165, p.410-9, 1993.

87. KONIKOFF, F. New mechanisms in cholesterol gallstone disease. Isr. J. Med. Sci., v.30, p.168-74, 1993. 
88. SÖMJEN, G.J.; GILAT, T. A non-micellar mode of cholesterol transport in human bile. Febs Letters, v.156, p. 265-8, 1983.

89. SÖMJEN, G.J.; MARIKOVSKY, Y.; LELKES, P.; GILAT, T. Cholesterol phospholipid vesicles in human bile: an ultrastructural study. Biochim. Biophys. Acta, v. 879, p.14-21, 1986.

90. LEE, S.P.; PARK, H.Z.; MADANI, H.; KALER, E.W. Partial characterization of a nonmicellar system of cholesterol solubilization in bile. Am. J. Physiol., v.252, p. G374-83, 1987.

91. CAREY, M.C.; LAMONT, J.T. Cholesterol gallstone formation. 1. Physicalchemistry of bile and biliary lipid secretion. Prog. Liver Dis., v.10, p.13964, 1992.

92. VERKADE, H.J.; VONK, R.J.; KUIPERS, F. New insights into the mechanism of bile acid induced biliary lipid secretion. Hepatology, v.21, p. 1174-89, 1995.

93. VAN ERPECUM, K.J.; VAN BERGE HENEGOUWEN, G.P. Pathogenetic factors in cholesterol gallstone disease. Scand. J. Gastroenterol., v.24, p.83-90, 1989. Supplement 171.

94. PAUMGARTNER, G.; SAUERBRUCH, T. Gallstone: pathogenesis. Lancet, v.338, p.1117-21, 1991.

95. JOHNSTON, D.E.; KAPLAN, M.M. Pathogenesis and treatment of gallstones. N. Engl. J. Med., v.328, p. 412-21, 1993. 
96. LAMONT, J.T.; CAREY, M.C. Cholesterol gallstone formation. 2. Pathobiology and pathomechanics. Prog. Liver Dis., v.10, p.165-91, 1992.

97. SHAFFER, E.A.; McORMOND, P.; DUGGAN, H. Quantitative cholescintigraphy: assessment of gallbladder filling and emptying and duodenogastric reflux. Gastroenterology, v.79, p.899-906, 1980.

98. THOMPSON, J.C.; FRIED, G.M.; OGDEN, W.D.; FAGAN, C.J.; INOUE, K.; WIENER, I.; WATSON, L.C. Correlation between release of cholecystokinin and contraction of the gallbladder in patients with gallstones. Ann. Surg., v.195, p. 670-6, 1982.

99. BOBBA, V.R.; KRISHNAMURTHY, G.T.; KINGSTON, E.; TURNER, F.E. Comparison of gallbladder dynamics in normal subjects and patients with gallstones. J. Nucl. Med., v.23, p.P28, 1982. [Resumo]

100. BOBBA, V.R.; KRISHNAMURTHY, G.T.; KINGSTON, E.; TURNER, F.E.; BROWN, P.H.; LANGRELL, K. Gallbladder dynamics induced by a fatty meal in normal subjects and patients with gallstones: concise communication. J. Nucl. Med., v.25, p.21-4, 1984.

101. MESGARZADEH， M.; KRISHNAMURTHY， G.T.; BOBBA， V.R.; KINGSTON, E. Biliary dynamics in health and in patients with cholelithiasis. J. Nucl. Med., v.23, p. P28, 1982. [Resumo] 
102. KRISHNAMURTHY, G.T.; BOBBA, V.R.; McCONNELL, D.; TURNER., F.; MESGARZADEH, M.; KINGSTON, E. Quantitative biliary dynamics: introduction of a new noninvasive scintigraphic technique. J. Nucl. Med., v. $217-23,1983$.

103. FISHER, R.S.; STELZER, F.; ROCK, E.; MALMUD, L.S. Abnormal gallbladder emptying in patients with gallstones. Dig. Dis. Sci., v.27, p.1019-24, 1982.

104. FORGACS, I.C.; MAISEY, M.N.; MURPHY, G.M.; DOWLING, R.H. Influence of gallstones and ursodeoxycholic acid therapy on gallbladder emptying. Gastroenterology, v.84, p.299-307, 1984.

105. POMERANZ, I.S.; SHAFFER, E.A. Abnormal gallbladder emptying in a subgroup of patients with gallstones. Gastroenterology, v.88, p.787-91, 1985.

106. KISHK, S.M,A; DARWEESH, R.M.A.; DODDS, W.J.; LAWSON, T.L.; STEWART, E.T.; KERN, M.K.; HASSANEIN, E.H. Sonographic evaluation of resting gallbladder volume and postprandial emptying in patients with gallstones. A.J.R., v.148, p.875-9, 1987.

107. UPP, J.R., Jr.; NEALON, W.H.; SINGH, P.; FAGAN, C.T.; JONAS, A.S.; GREELEY Jr., G.H.; THOMPSON, J.C. Correlation of cholecystokinin receptors with gallbladder contractility in patients with gallstones. Ann.Surg., v.205, p.641-8, 1987. 
108. SYLWESTROWICZ, T.A.; SHAFFER, E.A. Gallbladder function during gallstone dissolution: effect of bile acid therapy in patients with gallstones. Gastroenterology, v.95, p. 740-8, 1988.

109. SPENGLER, U.; SACKMANN， M.; SAUERBRUCH， T.; HOLL，J.; PAUMGARTNER, G. Gallbladder motility before and after extracorporeal shock- wave lithotripsy. Gastroenterology, v.96, p.860-3, 1989.

110. MASCLEE, A.A.M.; JANSEN, J.B.M.J.; DRIESSEN, W.M.M.; GEUSKENS, L.M.; LAMERS, C.B.H.W. Plasma cholecystokinin and gallbladder responses to intraduodenal fat in gallstone formation. Dig. Dis. Sci., v.34, p.353-9, 1989.

111. LEGMANN, P.; LEVESQUE, M.; POMMEZ-BOUdINET, C.; GUICHARD, J.P. Étude échographique de la contraction vésiculaire: aspects normal et pathologique: à propos de 115 patients. Ann. Radiol. (Paris), v.32, p.103-6, 1989.

112. FESTI, D.; FRABBONI, R.; BAZZOLI, F.; SANGERMANO, A.; RONCHI, M.; ROSSI, L.; PARINI, P.; ORSINI, M.; PRIMERANO, A.M.M.; MAZZELLA, G.; ALDINI, R.; RODA, E. Gallbladder motility in cholesterol gallstone disease. Effect of ursodeoxycholic acid administration and gallstone dissolution. Gastroenterology, v.99, p.1779-85, 1990.

113. VAN ERPECUM, K.J.; VAN BERGE HENEGOUWEN, G.P.; STOLK, M.F.J.; HOPMAN, W.P.M.; JANSEN, J.B.M.J.; LAMERS, C.B.H.W. Fasting gallbladder volume, postprandial emptying and cholecystokinin release in gallstone patients and normal subjects. J. Hepatol., v.14, p.194-202, 1992. 
114. PALASCIANO, G.; SERIO, G.; PORTINCASA, P.; PALMIERI, V.; FANELLI, M.; VELARDI, A.; CALO'GABRIELI, B.; VINCIGUERRA, V. Gallbladder volume in adults and relationship to age, sex, body mass index, and gallstones: a sonographic population study. Am. J. Gastroenterol., v.87, p.493-7, 1992.

115. CATNACH, S.M.; FAIRCLOUGH, P.D.; TREMBATH, R.C.; O'DONNELL, L.J.D.; McLEAN, A.M.; LAW, P.A.; WICKHAM, J.E.A. Effect of oral erythromycin on gallbladder motility in normal subjects and subjects with gallstones. Gastroenterology, v.102, p.2071-6, 1992.

116. BERR, F.; PRATSCHKE, E.; FISCHER, S.; PAUMGARTNER, G. Disorders of bile acid metabolism in cholesterol gallstone disease. J. Clin. Invest., v.90, p.859- 68, 1992.

117. PAULETZKI, J.; CICALA, M.; HOLL, J.; SAUERBRUCH, T.; SCHAFMAYER, A.; PAUMGARTNER, G. Correlation between gallbladder fasting volume and postprandial emptying in patients with gallstones and healthy controls. Gut, v.34, p.1443-7, 1993.

118. PORTINCASA, P.; DiCIAUlA, A.; BALDASSARRE, G.; PALMIERI, V.; GENTILE, A.; CIMMINO, A.; PALASCIANO, G. Gallbladder motor function in gallstone patients: sonographic and in vitro studies on the role of gallstones, smooth muscle function and gallbladder wall inflamation. J. Hepatol., v.21, p.430-40, 1994. 
119. PORTINCASA, P.; Di CIAULA, A.; PALMIERI, V.O.; BALDASSARRE, G.; PALASCIANO, G. Enhancement of gallbladder emptying in gallstone patients after oral cholestyramine. Am. J. Gastroenterol., v.89, p.909-14, 1994.

120. BERR, F.; MAYER, M.; SACKMANN, M.F.; SAUERBRUCH, T.; HOLL, J.; PAUMGARTNER, G. Pathogenic factors in early recurrence of cholesterol gallstones. Gastroenterology, v.106, p.215-24, 1994.

121. PAUlETZKI, J.; CICALA, M.; SPENGLER, U.; SAUERBRUCH, T.; PAUMGARTNER, G. Gallbladder emptying during high-dose cholecystokinin infusions: effect in patients with gallstone disease and healthy controls. Scand. J. Gastroenterol., v.30, p.128-32, 1995.

122. SHODA, J.; HE, B.; TANAKA, N.; MATSUZACHI, Y; OSUGA, T.; YAMAMORI, S.; MIYAZAKI, H.; SJÖVALL, J. Increase of deoxycholate in supersaturared bile of patients with cholesterol gallstone diseade and its correlation with de novo synthesis of cholesterol and bile acids in liver, gallbladder emptying, and small intestinal transit. Hepatology, v.21, p.1291-1302, 1995.

123. MEYER, P.D.; DenBESTEN, L.; GURLL, N.J. Effects of cholesterol gallstone induction on gallbladder function and bile salt pool size in the prairie dog model. Surgery, v.83. p.599-604, 1978. 
124. FRIDHANDLER, T.M.; DAVISON, J.S.; SHAFFER, E.A. Defective gallbladder contractility in the ground squirrel and prairie dog during the early stages of cholesterol gallstone formation. Gastroenterology, v.85, p.830-6, 1983.

125. DOTY, J.E.; PITT, H.A.; KUCHENBECKER, S.L.; DenBESTEN, L. Impaired gallbladder emptying before gallstone formation in the prairie dog. Gastroenterology, v.85, p.168-74, 1983.

126. PELLEGRINI, C.A.; RYAN, T.; BRODERICK, W.; WAY, L.W. Gallbladder filling and empyting during cholesterol gallstone formation in the prairie dog: a cholescintigraphic study. Gastroenterology, v.90, p.143-9, 1986.

127. LI, Y.F.; MOODY, F.G.; WEISBRODT, N.W.; ZALEWSKY, C.A.; COELHO, J.C.U.; SENNINGER, N.; GOUMA, D. Gallbladder contractility and mucus secretion after cholesterol feeding in the prairie dog. Surgery, v.100, p. $900-4,1986$.

128. LI, Y.F.; WEISBRODT, N.W.; MOODY, F.G.; COELHO, J.C.; GOUMA, D.J. Calcium-induced contraction and contractile protein content of gallbladder smooth muscle after high cholesterol feeding of prairie dogs. Gastroenterology. v.92, p.746-50, 1987.

129. CHAPMAN, W.C.; PETERKIN, G.A.; La MORTE, W.W.; WILLIAMS, L.F. Jr. Alterations in biliary motility correlate with increased gallbladder prostaglandin synthesis in early cholelithiasis in prairie dog. Dig.Dis.Sci., v.34, p.1420-4, 1989. 
130. ROSLYN, J.J.; DenBESTEN, L.; PITT, H.A.; KUCKENBECKER, S.; POLAREK, J.W. Effects of cholecystokinin on gallbladder stasis and cholesterol gallstone formation. J.Surg.Res., v.30, p.200-4, 1981.

131. BRUGGE, W.R.; BRAND, D.L.; ATKINS, H.L.; LANE, B.P.; ABEL, W.G. Gallbladder dyskinesia in chronic acalculous cholecystitis. Dig.Dis.Sci., v. 31, p.461-7, 1986

132. ISHIZUKA, J.; SHIMODA, I.; MURAKAMI, M.; SATO, K.; HIRANO, H.; TANNO, N.; KOIZUMI, M.; TOYOTA, T. Conservative therapy of gallbladderstones. Gastroenterology, v. 96, p. A229, 1989. [Resumo]

133. BOLONDI, L.; GAIANI, S.; TESTA, S.; LABO, G. Gallbladder sludge formation during prolonged fasting after gastrointestinal tract surgery. Gut, v.26, p. 734-8, 1985.

134. BARTH, R.A.; BRASCH, R.C.; FILLY, R.A. Abdominal pseudotumor in childhood: distended gallbladder with parenteral hyperalimentation. A.J.R., v. 136, p.341-3, 1981.

135. ROSLYN, J.J.; PITT, H.A.; MANN, L.L.; AMENT, M.E.; DenBESTEN, L. Gallbladder disease in patients on long-term parenteral nutrition. Gastroenterology, v. 84, p. 148-54, 1983.

136. HOLZBACH, R.T. Gallbladder stasis: consequence of long-term parenteral hyperalimentation and risk factor of cholelithiasis. Gastroenterology, v. 84, p.1055-8, 1983. 
137. MESSING, B.; BORIES, C.; KUNSTLINGER, F.; BERNIER, J.J. Does total parenteral nutrition induce gallbladder sludge formation and lithiasis? Gastroenterology, v. 84, p.1012-19, 1983.

138. CANO, N.; CICERO, F.; RANIERI, F.; MARTIN, J.; DiCONSTANZO, J. Ultrasonographic study of gallbladder motility during total parenteral nutrition. Gastroenterology, v. 91, p.313-7, 1986.

139. SITZMANN, J.V.; PITT, H.A.; STEINBORN, P.A.; PASHA, Z.R.; SANDERS, R.C. Cholecystokinin prevents parenteral nutrition induced biliary sludge in humans. Surg.Gynecol. Obstet., v.170, p. 25-31, 1990.

140. FEIN, B.I.; HOLT, P.R. Hepatobiliary complications of total parenteral nutrition. J. Clin. Gastroenterol., v.18, p.62-6, 1994.

141. APSTEIN, M.D.; DALECKI-CHIPPERFIELD, K. Spinal cord injury is a risk factor for gallstone disease. Gastroenterology, v. 92, p.966-8, 1984.

142. APSTEIN, M.D.; GEORGE, B.; TCHAKAROVA, B. The incidence of gallstones following spinal cord injury: a prospective study. Hepatology, v.16, p. 154A, 1992. [Resumo]

143. BRAVERMAN, D.Z.; JOHNSON, M.L.; KERN, F, Jr. Effects of pregnancy and contraceptive steroids on gallbladder function. N. Engl. J. Med., v.302, p.362-4, 1980. 
144. KERN, F. Jr.; EVERSON, G.T.; De MARK, B.; McKINLEY, C.; SHOWALTER, R.; ERFLING, W.; BRAVERMAN, D.Z.; SZCZEPANIKVAN LEEUWEN, P.; KLEIN, P.D. Biliary lipids, bile acids, and gallbladder function in the human female: effects of pregnancy and the ovulatory cycle. J. Clin. Invest., v.68, p.1229-42, 1981.

145. MARINGHINI, A.; CIAMBRA, M.; BACCELLIERI, P.; RAIMONDO, M.; PAGLIARO, L. Sludge, stones and pregnancy. Gastroenterology, v.95, p.1160-1, 1988.

146. EVERSON, G.T.; McKINLEY, C.; LAWSON, M.; JOHNSON, M.; KERN, F. Jr. Gallbladder function in the human female: effect of the ovulatory cycle, pregnancy and contraceptive steroids. Gastroenterology, v.82, p.711-9, 1982.

147. BOSTON COLLABORATIVE DRUG SURVEILLANCE PROGRAM. Oral contraceptive and venous tromboembolic disease, surgically confirmed gallbladder disease, and breast tumours. Lancet, v.1, p.1399-1404, 1973.

148. BENNION, L.J.; GRUNDY, S.M. Risk factors for the development of cholelithiasis in man. N. Engl. J. Med., v.299, p.1221-7, 1978.

149. SHAFFER, E.A.; TAYLOR, P.J.; LOGAN, K.; GADOMSKI, S.; CORENBLUM, P. The effect of a progestin on gallbladder function in young women. Am. J. Obstet. Gynecol., v.148, p.504-7, 1984. 
150. KERN, F. Jr.; EVERSON, G.T.; DeMARK, B.; McKINLEY, C.; SHOWALTER, R.; BRAVERMAN, D.Z. SZCZEPANIK-VAN LEEUWEN, P.; KLEIN, P.D. Biliary lipids, bile acids, and gallbladder function in the human female: effects of contraceptive steroids. J. Lab. Clin. Med., v.99, p.798-805, 1982.

151. KEANE. P.; COLWELL, D.; BAER, H.P.; CLANACHAN, A.S.; SCOTT, G.W. Effects of age, gender and female sex hormones upon contractility of the human gallbladder in vitro. Surg. Gynecol. Obstet., v.163, p.555-60, 1986.

152. KUCIO, C.; BESSER, P.; JONDERKO, K. Gallbladder motor function in obese versus lean females. Eur. J. Clin. Nutr., v.42, p.121-4, 1988.

153. VEZINA, W.C.; PARADIS, R.L. ; GRACE, D.M.; ZIMMER, R.A.; LAMONT, D.D.; RYCROFT, K.M.; KING, M.E.; HUTTON, L.C.; CHEY, W.Y. Increased volume and decreased emptying of the gallbladder in large (morbidly obese, tall normal, and muscular normal) people. Gastroenterology, v. 98, p.1000-7, 1990.

154. MARZIO, L.; CAPONE, F.; NERI, M.; MAZZETTI, A.; De ANGELIS, C.; CUCCURULLO, F. Gallbladder kinetics in obese patients: effect of a regular meal and low calorie meal. Dig. Dis. Sci., v.33, p.4-9, 1988.

155. EVERHART, J.E. Contributions of obesity and weight loss to gallstone disease. Ann. Intern. Med., v.119, p.1029-35, 1993. 
156. WISÉN, O.; HELLSTRÖM, P.M. Gastrointestinal motility in obesity. J. Intern. Med., v.237, p.411-8, 1995.

157. STONE, B.G.; GAVALER, J.S.; BELLE, S.H.; SHREINER, D.P. ; PELEMAN, R.R.; SARVA, R.P.; YINGVORAPANT, N.; VAN THIEL, D.H. Impairment of gallbladder emptying in diabetes mellitus. Gastroenterology, v. 95, p.170-6, 1988.

158. PALASCIANO, G.; PORTINCASA, P.; BELFIORE, A.; BALDASSARRE, G.; CIGNARELli, M.; PATERNOSTRO, A.; ALBANO, O.; GIORGINO, R. Gallbladder volume and emptying in diabetics: the role of neuropathy and obesity. J. Intern. Med., v.231, p. 123-7, 1992.

159. FIORUCCI, S.; BOSSO, R.; SCIONTI, L.; DISANTO, S.; ANNIBALE, B.; DELLE-FAVE, G. Neurohormonal control of gallbladder motility in healthy subjects and diabetic patients with or without autonomic neuropathy. Dig. Dis. Sci., v.35, p. 1089- 97, 1990.

160. ABRAHAMSSON, H. Gastrointestinal motility disorders in patients with diabetes mellitus. J. Intern. Med., v. 237, p. 403-9, 1995.

161. KREJS, G.J.; ORCI, L.; CONLON, J.M.; RAVAZZOLA, M.; DAVIS, G.R.; RASKIN, P.; COLLINS, S.M.; McCARTHY, D.M.; BAETENS, D.; RUBENSTEIN, A.; ALDOR, T.A.M.; UNGER, R.H. Somatostatinoma syndrome: biochemical, morphological and clinical features. N. Engl. J. Med., v.301, p.285-8, 1979. 
162. LEMBCKE, B.; CREUTZFELDT, W.; SCHLESER, S.; EBERT, R.; SHAW, C.; KOOP, I. Effect of the somatostanin analogue sandostatin (SMS 201995) on gastrointestinal, pancreatic and biliary function and hormone release in normal men. Digestion, v.36, p.108-24, 1987.

163. GULLO, L.; BOLONDI, L.; SCARPIGNATO, C.; PRIORI, P.; CASANOVA, P.; LABÒ, G. Effect of somatostatin and thyrotropin - releasing hormone on cholecystokinin - induced gallbladder emptying. Dig. Dis. Sci., v.31, p.1345-50, 1986.

164. FISHER, R.S.; ROCK, E.; LEVIN, G.; MALMUD, L. Effects of somatostatin on gallbladder emptying. Gastroenterology, v. 92, p.885-90, 1987.

165. AHRENDT, S.A; McGUIRE, G.E.; PITT, H.A.; LILLEMOE, K.D. Why does somatostatin cause gallstones? Am. J. Surg., v.161, p.177-83, 1991.

166. MOSER, A.J.; ABEDIN, M.Z.; GIURGIU, D.I.N.; ROSLYN, J.J. Octreotide promotes gallbladder absorption in prairie dogs: a potential cause of gallstones. Gastroenterology, v. 108, p.1547-55, 1995.

167. EVERSON, G.T.; NEMETH, A.; KOUROURIAN, S.; ZOGG, D.; LEFF, N.B.; DIXON, D.; GITHENS, J.H.; PRETORIUS, D. Gallbladder function is altered in sickle hemoglobinopathy. Gastroenterology, v. 96, p.1307-16, 1989

168. MURRAY, F.E.; McNICHOLAS, M.; STACK, W.; O'DONOGHUE, D.P. Impaired fatty meal - stimulated gallbladder contractility in patients with Crohn's disease. Clin. Sci., v.83, p.689-93, 1992. 
169. HUTCHINSON, R.; TYRRELL, P.N.M.; KUMAR, D.; DUNN, J.A.; LI, J.K.W.; ALLAN, R.N. Pathogenesis of gallstones in Crohn's disease: an alternative explanation. Gut, v.35, p.94-7, 1994.

170. HAUTERS, P.; deNEVEdeRODEN, A.; POURBAIX, A.; AUPAIX, F.; COUMANS, P.; THERASSE, G. Cholelithiasis: a serious complication after total gastrectomy. Br. J. Surg., v.75, p.899-900, 1988.

171. MARZIO, L.; DifEliCE, F.; CELIBERTI, V.; DiGIOACCHINO, M.; MEZZETTI, A.; CUCCUROLLO, F.; INNOCENTI, P. Gallbladder emptying in duodenal ulcer patients having undergone Billroth II gastrectomy . Digestion, v. 41, p. 223-8, 1988.

172. POMERANZ, I.S.; DAVISON, J.S.; SHAFFER, E.A. The effects of prosthetic gallstones on gallbladder function and bile composition. J. Surg. Res., v.41, p.47-52, 1986 .

173. RAWAT, B.; FACHE, J.S.; BURHENNE, H.J. Altered gallbladder contractility after extracorporeal shock-wave cholecystolithotripsy. A.J.R., v.157, p. 485-9, 1991.

174. DONALD, J.J.; FACHE, J.S.; BURHENNE, H.J. Biliary lithotripsy: correlation between gallbladder contractility before treatment and the success of treatment. A.J.R., v.157, p.287-90, 1991. 
175. JANOWITZ, P.; WECHSLER, J.G.; KUHN, K.; KRATZER, W.; TUDYKA, J.; MAIER, C.; DITSCHUNEIT, H. Increased gallbladder residual volume in nonresponders to extracorporeal shock wave lithotripsy of gallbladder stones. Am. J. Gastroenterol., v.87, p. 1429-32, 1992.

176. SACKMANN, M.; EDER, H.; SPENGLER, U.; PAULETZKI, J.; HOLL, J.; PAUMGARTNER, G.; SAUERBRUCH, T. Gallbladder emptying is an important factor in fragment disappearance after shock wave lithotripsy. J. Hepatol., v.17, p.62-6, 1993.

177. VAN DER WERF, S.D.J.; VAN BERGE HENEGOUWEN, G.P.; PALSMA, D.M.H.; RUBEN, A.Th. Motor function of the gallbladder and cholesterol saturation of duodenal bile. Neth. J. Med., v.30, p.160-71, 1987.

178. BEHAR, J.; LEE, K.Y.; THOMPSON, W.R.; BIANCANI, P. Gallbladder contraction in patients with pigment and cholesterol stones. Gastroenterology, v.97, p.1479-84, 1989.

179. YU, P.; CHEN, Q.; BIANCANI, P.; BEHAR, J. Excess membrane cholesterol impairs gallbladder muscle contraction. Gastroenterology, v. 108, p. A442, 1995. [Resumo]

180. POSTON，G.J.; SINGH，P.; DRAVIAM，E.; YAO，C.Z.; GOMEZ，G.; THOMPSON, J.C. Early stages of gallstone formation in guinea pig are associated with decreased biliary sensitivity to cholecystokinin. Dig. Dis. Sci., v.37, p.1236-44, 1992. 
181. DAIGNAUlT, P.G.; FAZEKAS, A.G.; ROSENTHAL, L.; FRIED, G.M. Relationship between gallbladder contraction and progesterone receptors in patients with gallstones. Am. J. Surg., v.155, p.147-51, 1988.

182. HOULD, F.S.; FRIED, G.M.; FAZEKAS, A.G.; TREMBLAY, S.; MERSEREAU, W.A. Progesterone receptors regulate gallbladder motility. J. Surg. Res., v.45, p.505-12, 1988.

183. HARVEY, P.R.C.; McLEOD, R.S.; COHEN, Z.; STRASBERG, S.M. Effect of colectomy on bile composition, cholesterol crystal formation and gallstones in patients with ulcerative colitis. Ann. Surg., v. 214, p.396-402, 1991.

184. KURCHIN, A.; RAY, J.E.; BLUTH, E.I.; MERRITT, C.R.B.; GATHRIGHT, J.B.; PEHRSSON, B.F.; FERRARI, B.T. Cholelithiasis in ileostomy patients. Dis. Colon Rectum, v.27, p.585-8, 1984.

185. BLUTH, E.I.; MERRITT, C.R.B.; SULLIVAN, M.A.; KURCHIN, A.; RAY, J.E. Inflammatory bowel disease and cholelithiasis: the association in patients with an ileostomy. South Med. J., v.77, p.690-2, 1984.

186. DODDS, W.J.; GROH, W.J.; DARWEESH, R.M.A.; LAWSON, T.L.; KISHK, S.M.A.; KERN, M.K. Sonographic measurement of gallbladder volume. A.J.R., v.145, p. 1009-11, 1985. 
187. WEDMANN, B.; SCHMIDT, G.; WEGENER, M.; COENEN, C.; RICKEN, D.; DRÖGE, C. Sonographic evaluation of gallbladder kinetics: in vitro and in vivo comparison of different methods to assess gallbladder emptying. J. Clin. Ultrasound, v.19, p.341-9, 1991.

188. BOLONDI, L.; BORTOLOTTI, M.; SANTI, V.; CALLETTI, T.; GAIANI, S.; LABÒ, G. Measurement of gastric emptying time by real time ultrasonography. Gastroenterology, v. 89, p.752-9, 1985.

189. LAWSON, M.; EVERSON, G.T.; KLINGENSMITH, W.; KERN, F. Jr. Coordination of gastric and gallbladder emptying after ingestion of a regular meal. Gastroenterology, v. 85, p. 866-70, 1983.

190. FRIED, M.; MAYER, E.A.; JANSEN, J.B.M.J.; LAMERS, C.B.H.W.; TAYLOR, I.L; BLOOM, S.R.; MEYER, J.H. Temporal relationships of cholecystokinin release, pancreatobiliary secretion, and gastric emptying of a mixed meal. Gastroenterology, v. 95, p.1344-50, 1988.

191. FROEHLICH, F.; GONVERS, J.J.; FRIED, M. Role of nutrient fat and cholecystokinin in regulation of gallbladder emptying in man. Dig. Dis. Sci., v.40, p.529-33, 1995.

192. SHERLOCK, S.; DOOLEY, J. Diseases of the liver and biliary system. 9. ed. London, Blackwell Scientific Publications, 1993. Cap. 29, p. 532-47: Imaging of the biliary tract: interventional radiology and endoscopy. 
193. SPIRO, H.M. Clinical Gastroenterology. 4. ed. New York, McGraw Hill, Inc., 1993. Cap. 40, p.839-55: Gallbladder and biliary tree disorders: general considerations.

194. MALATJALIAN, M.D. Pitfalls in the histological diagnosis of inflammatory bowel disease on colorectal biopsies. Can. J. Gastroenterol., v.4, p.33640, 1990.

195. MORSON, B.C.; DAWSON, I.M.P. Morson \& Dawson's Gastrointestinal Pathology. 3. ed. Oxford, Blackwell Scientific Publications, 1990. Cap. 37, v.2, p.477-549: Large intestine: inflammatory disorders.

196. DAMIÃO, A.O.M.C.; HABR-GAMA, A. Retocolite ulcerativa idiopática. In: DANI, R.; PAULA-CASTRO, L., ed. Gastroenterologia Clínica, 3. ed. Rio de Janeiro, Editora Guanabara Koogan S.A., 1993. v.1, p. 1037-76.

197. GELLER, S.A. Pathology of inflammatory bowel disease: a critical appraisal in diagnosis and management. In: TARGAN, S.R.; SHANAHAN, F. ed. Inflammatory bowel disease: from bench to bedside. Baltimore, Williams \& Wilkins, 1994. p. 336-51.

198. RUBINSTEIN, M.C.; FISHER, R.L. New therapies for idiopathic ulcerative colitis. The Gastroenterologist, v.1, p.71-82, 1993.

199. KUMAR, D. Ulcerative colitis: surgical options. In: KUMAR, D.; ALEXANDER-WILLIAMS, J., ed. Crohn's disease and ulcerative colitis: surgical management. London, Springler Verlag, 1993. p. 169-75. 
200. KUMAR, D. Ulcerative colitis: the operation. In: KUMAR, D.; ALEXANDER-WILLIAMS, J., ed. Crohn's disease and ulcerative colitis: surgical management. London, Springler Verlag, 1993. p. 183-96.

201. BECK, D.E.; GATHRIGHT, J.B. Jr. Ulcerative colitis: surgical indications and alternatives. South Med. J., v.87, p.773-9, 1994.

202. SAGAR, P.M.; TAYLOR, B.A. Pelvic ileal reservoirs: the options. Brit. J. Surg., v.81, p.325-32, 1994.

203. JACOBS, D.O.; BECKER, J.M. Surgical management of ulcarative colitis. In: TARGAN, S.R.; SHANAHAN, F., ed. Inflammatory bowel disease: from bench to bedside. Baltimore, Williams \& Wilkins, 1994. p. 567-81.

204. SOOD, G.K.; BAIJAL, S.S; LAHOTI, D.; BOOR, S.L. Abnormal gallbladder function in patients with irritable bowel syndrome. Am. J. Gastroenterol., v.88, p. 1387-90, 1993.

205. FARMER, R.G. Nonspecific ulcerative proctitis. Gastroenterol. Clin. North Am., v.16, p.154-74, 1987.

206. SEO, M.; OKADA, M.; YAO, T.; UEKI, M.; ARIMA, S.; OKUMURA, M. An index of disease activity in patients with ulcerative colitis. Am. J. Gastroenterol., v.87, p.971-6, 1992.

207. ROSNER, B. Fundamentals of biostatistics. 2. ed. Harvard University, Boston, Massachusetts, Duxbury Press, 1986. Cap. 10, p. 302-68: Hypothesis testing: categorical data. 
208. FLEISS, J.L. Statistical methods for rates and proportions. 2. ed. New York, John Wiley \& Sons, 1981. Cap. 9, p. 138-59: The comparison of proportions from several independent samples.

209. ROSNER, B. Fundamentals of biostatistics. 2. ed. Harvard University, Boston, Massachusetts, Duxbury Press, 1986. Cap. 12, p. 442-89: Analysis of variance.

210. TIMM, N.H. Multivariate analysis with applications in Education and Psychology. Monterey, California Brooks/Cole Publising Company, 1975. Cap. 5, p.359-527: Multivariate analysis of variance and covariance analysis.

211. ROSNER, B. Fundamentals of biostatistics. 2. ed. Harvard University, Boston, Massachusetts, Duxbury Press, 1986. Cap. 11, p. 369-441: Regression and correlation methods.

212. AKERLUND, J.; BJÖRKHEM, I.; ANGELIN, B.; LILJEQVIST, L.; EINARSSON, K. Apparent selective bile acid malabsorption as a consequence of ileal exclusion: effects on bile acid, cholesterol, and lipoprotein metabolism. Gut, v.35, p.1116-20, 1994.

213. MURRAY, F.E.; STINCHCOMBE, S.J.; HAWKEY, C.J. Effect of indomethacin and misoprostol on fasted gallbladder volume and mealinduced gallbladder contractility in humans. Dig. Dis. Sci., v.34, p.1228-31, 1992. 
214. HOFMANN, A.F. Pathogenesis of cholesterol gallstones. J. Clin. Gastroenterol., v.10, p.S1-11, 1988.

215. LANZINI, A.; NORTHFIELD, T.C. Assessment of the motor functions of the gallbladder. J. Hepatol., v.9, p.383-91, 1989.

216. CHAPMAN, R.W. Inflammatory bowel disease: hepatobiliary disease. In: ALLAN, R.N.; KEIGHLEY, M.R.B.; ALEXANDER-WILLIAMS, J.; HAWKINS, C.F., ed. Inflammatory bowel diseases. 2. ed. Edinburgh, Churchill Livingstone, 1990. p. 513-22.

217. BAKER, A.L.; KAPLAN, M.M.; NORTON, R.A.; PATTERSON, J.F. Gallstones in inflammatory bowel disease. Dig. Dis., v.19, p. 109-12, 1974.

218. MAKINO, I,; CHIJIIWA, K.; HIGASHIJIMA, H.; NAKAHARA, S.; KISHINAKA, M.; KUROKI, S.; MIBU, R. Rapid cholesterol nucleation time and cholesterol gallstone formation after subtotal or total colectomy in humans. Gut, v.35, p. 1760-4, 1994.

219. MALAGELADA, J.R.; GO, V.L.W.; Di MAGNO, E.P., SUMMERSKILL, W.H.J. Interactions between intraluminal bile acids and digestive products on pancreatic and gallbladder function. J. Clin. Invest., v.52, p. 2160-5, 1973.

220. GOMEZ, G.; LLUIS, F.; GUO, Y.; GREELEY, G.H. Jr.; TOWNSEND, C.M. Jr.; THOMPSON, J.C. Bile inhibits release of cholecystokinin and neurotensin. Surgery, v.100, p. 363-8, 1986. 
221. GOMEZ, G.; UPP, J.R. Jr.; LLUIS, F.; ALEXANDER, R.W.; POSTON, G.J.; GREELEY, G.H. Jr.; THOMPSON, J.C. Regulation of the release of cholecystokinin by bile salts in dogs and humans. Gastroenterology, v.94. p.1036-46, 1988.

222. KOOP, I.; FELLGIEBEL, A.; KOOP, H.; SCHAFMAYER, A.; ARNOLD, R. Effect of cholestyramine on plasma cholecystokinin and pancreatic polypeptide levels, and exocrine pancreatic secretion. Eur. J. Clin. Invest., v.18, p.517-23, 1988 .

223. GOMEZ, G.; TOWNSEND, C.M. Jr.; MAANI, R.; SINGH, P.; GREELEY, G.H. Jr.; THOMPSON, J.C. Down-regulation of pancreatic growth and gallbladder contractility by bile salts. Am. J. Surg., v.157, p. 20-6, 1989.

224. KOOP, I.; DORN, S.; KOOP, H.; WITZLEB, S.; BEGLINGER, C.; SCHAFMAYER, A.; ARNOLD, R. Dissociation of cholecystokinin and pancreatobiliary response to intraduodenal bile acids and cholestyramine in humans. Dig. Dis. Sci., v.36, p.1625-32, 1991.

225. KAY, R.M.; COHEN, Z.; SIU, K.P.; PETRUNKA, C.N.; STRASBERG, S.M. Ileal excretion and bacterial modification of bile acids and cholesterol in patients with continent ileostomy. Gut, v.21, p.128-32, 1979.

226. ANDERSSON, H.; FASTH, S.; FILIPSSON, S.; HELLBERG, R.; HULTÉN, L.; NILSSON, L.O; NORDGREN, S.; KOCK, N.G. Faecal excretion of intravenously injected $14 \mathrm{C}$ - cholic acid in patients with conventional ileostomy and in patients with continent ileostomy reservoir. Scand. J. Gastroenterol., v.14, p.551-4, 1979. 
227. PEDERSEN, B.H.; SIMONSEN, L.; HANSEN, L.K.; GIESE, B.; JUSTESEN, T.; TOUGAARD, L.; BINDER, V. Bile acid malabsorption in patients with an ileum reservoir with a long efferent leg to an anal anastomosis. Scand. J. Gastroenterol., v. 20, p.995-1000, 1985.

228. HYLANDER, E.; LADEFOGED, K.; NIELSEN, M.L.; NIELSEN, O.V.; THALE, M.; JARNUM, S. Excretion, deconjugation and absorption of bile acids after colectomy for ulcerative colitis. Scand. J. Gastroenterol., v. 21, p.1137-43, 1986.

229. FIORENTINI, M.T.; LOCATELLI, L.; CECCOPIERI, B.; BERTOLINO, F.; OSTELlinO, O.; BARLOTTA, A.; ROLFO, P.; FERRARIS, P.; de la PIERRE, M.; DELLEPIANE, M. Physiology of ileoanal anastomosis with ileal reservoir for ulcerative colitis and adenomatosis coli. Dis. Colon Rectum, v.30, p.267-72, 1987.

230. NASMYTH, D.G.; JOHNSTON, D.; WILLIAMS, N.S.; KING, R.F.G.J.; BURKINSHAW, L.; BROOKS, K. Changes in the absorption of bile acids after total colectomy in patients with an ileostomy or pouch-anal anastomosis. Dis. Colon Rectum, v.32, p.230-4, 1989.

231. NATORI, H.; UTSUNOMIYA, J.; YAMAMURA, T.; BENNO, Y.; UCHIDA, K. Fecal and stomal bile acid composition after ileostomy or ileoanal anastomosis in patients with chronic ulcerative colitis and adenomatosis coli. Gastroenterology, v.102, p.1278-88, 1992. 
232. SALEMANS, J.M.J.I.; NAGENGAST, F.M.; TANGERMAN, A.; VAN SCHAIK, A.; De HAAN, A.F.J.; JANSEN, J.B.M.J. Postprandial conjugated and unconjugated serum bile acid levels after proctocolectomy with ileal pouch-anal anastomosis. Scand. J. Gastroenterol., v. 28, p.78690, 1993.

233. KOTWALL, C.A.; CLANACHAN, A.S.; BAIE, H.P. Effect of prostaglandins on motility of gallbladder removed from patients with gallstones. Arch. Surg., v.119, p.709-12, 1984.

234. GREAVES, R.R.S.H.; O'DONNELL, L.J.D.; FARTHING, M.J.G. Prostaglandins are potent prokinetics for human gallbladder in vitro. Gastroenterology, v. 108, p. A416, 1995. [Resumo]

235. GO, P.M.N.Y.H.; VAN DIEIJEN-VISSER, M.P.; DAVIES, B.I.; LENS, J.; BROMBACHER, P.J. Microbial flora and bile acid metabolism in patients with an ileal reservoir. Scand. J. Gastroenterol., v.23, p.229-36, 1988.

236. PHILIPSON, B.; BRANDBERG, A.; JAGENBURG, R.; KOCK, N.G; LAGER, I.; AHRÉN, C. Mucosal morphology, bacteriology, and absorption in intraabdominal ileostomy reservoir. Scand. J. Gastroenterol., v. 10, p.145-53, 1975.

237. LERCH, M.M.; BRAUN, J.; HARDER, M.; HOFSTÄDTER, F.; SCHUMPELICK, V.; MATERN, S. Postoperative adaptation of the small intestine after total colectomy and J - pouch-anal anastomosis. Dis. Colon Rectum, v.32, p.600-8, 1989. 
238. SANTOS, M.C.; THOMPSON, J.S. Late complications of the ileal pouch-anal anastomosis. Am. J. Gastroenterol., v.88, p.3-10, 1993.

239. SANTAVIRTA, J.; MATTILA, J.; KOKKI, M.; PÖYHÖNEN, L.; MATIKAINEN, M. Absorption of bile acids after ileoanal anastomosis. Ann. Chir. Gynaecol., v.79, p.134-8, 1990.

240. VAN ERPECUM, K.J.; VAN BERGE HENEGOUWEN, G.P.; STOLK, M.F.J.; HOPMAN, W.P.M.; JANSEN, J.B.M.J.; LAMERS, C.B..H.W. Effects of ursodeoxycholic acid on gallbladder contraction and cholecystokinin release in gallstone patients and normal subjects. Gastroenterology, v.99, p.836$42,1990$.

241. O'DONNELL, L.J.D.; WILSON, P.; GUEST, P.; CATNACH, S.M.; McLEAN, A.; WICKHAM, J.E.A.; FAIRCLOUGH, P.D. Indomethacin and postprandial gallbladder emptying. Lancet, v.269-71, 1992.

242. FIORUCCI, S.; DISTRUTTI, E.; GERLI, R.; MORELLI, A. Effect of erythromycin on gastric and gallbladder emptying and gastrointestinal symptoms inscleroderma patients is maintained medium term. Am. J. Gastroenterol., v.89, p. 550-5, 1994.

243. THORENS, J.; SCHNEGG, J.F.; BRIGNOLI, R.; FROEHLICH, F.; JANSEN, J.B.; DORTA, G.; BLUM, A.L.; GONVERS, J.J.; FRIED, M. Effect of cisapride on gallbladder motility after extracorporeal shock - wave lithotripsy. J. Hepatol., v.22, p.333-7, 1995. 
244. AGARWAL, B.; MEHTA, P.; SALUJA, S.; SETHURAMAN, K.R. Erythromycinameliorates abnormal gallbladder contraction in diabetic autonomic neuropathy. Gastroenterology, v.108, p. A404, 1995. [Resumo]

245. XU, O; SCOTT, R.B.; TAN, D.T.M.; SHAFFER, E.A. Erythromycin as aprokinetic agent in an animal model of cholesterol gallstone disease. Gastroenterology, v. 108, p. A441, 1995. [Resumo] 


\section{Summary}

Patients with ulcerative colitis, who have their colon removed, are at increased risk of developing cholesterol gallstones. Gallbladder hypomotility has been quoted as being an important factor for cholesterol gallstone formation, together with biliary supersaturation of cholesterol and nucleation of cholesterol crystals (nucleating and antinucleating factors). Gallbladder stasis increases the time for water reabsorption by the gallbladder mucosa with ensuing solute superconcentration; moreover, gallbladder stasis renders enough time for cholesterol nucleation, crystal retention and fusion, and finally, stone formation. Although bile composition, in these patients, has already been studied, there is no information concerning the nature of gallbladder motility in patients with ulcerative colitis with or without colectomy. In the present work, gallbladder emptying was studied by means of ultrasound examination, and after ingestion of a standard liquid fatty meal in controls $(n=40)$, ulcerative colitis patients without colectomy $(n=30)$ and with colectomy $(n=20)$. Also, in order to rule out the influence of gastric emptying on gallbladder motility, the gastric emptying time was calculated, in the three groups, using the ultrasound method. Gallbladder emptying was significantly impaired in patients with ulcerative colitis with colectomy after a fatty-meal stimulus, and this abnormality was not a consequence of delayed gastric emptying, since gastric emptying time was similar in the three groups. Furthermore, impaired gallbladder motility in ulcerative colitis patients with colectomy was related to the colectomy itself, since controls and ulcerative colitis 
patients without colectomy disclosed similar results pertaining to gallbladder emptying. In addition to that, our data point out the importance of gallbladder motility in cholelithiasis and its role, together with the diminished bile acid pool, in the pathogenesis of cholesterol gallstones in patients with ulcerative colitis who were subjected to colectomy. 